\title{
Mathematical Model of the Transmission Dynamics of Lassa Fever Infection with Controls
}

\author{
Sambo Dachollom ${ }^{1, *}$, Chinwendu Emilian Madubueze ${ }^{2}$ \\ ${ }^{1}$ Department of Mathematics/Statistics, School of Science, Akanu Ibiam Federal Polytechnic, Unwana, Afikpo, Nigeria \\ ${ }^{2}$ Department of Mathematics/Statistics/Computer Science, University of Agriculture Makurdi, Markurdi, Nigeria
}

Email address:

dachollomsambo@gmail.com (S. Dachollom)

${ }^{*}$ Corresponding author

To cite this article:

Sambo Dachollom, Chinwendu Emilian Madubueze. Mathematical Model of The Transmission Dynamics of Lassa Fever Infection with Controls. Mathematical Modelling and Applications. Vol. 5, No. 2, 2020, pp. 65-86. doi: 10.11648/j.mma.20200502.13

Received: February 23, 2020; Accepted: March 16, 2020; Published: March 31, 2020

\begin{abstract}
After fifty years of documented history of Lassa fever in Nigeria, the country is still recording the highest record of outbreaks worldwide with Ebonyi state been the most affected state in the whole of Eastern Nigeria. This has activated interventional measures coming from both the government and scholars. The government through the Nigeria Centre for Disease Control (NCDC) and other sister agencies has activated an emergency response by establishing management centres which operates in association with specialist teaching hospitals in the endemic states, the scholars on the other hand are approaching the menace from two broad but complimentary aspects of sciences namely; the medical sciences and the natural sciences. The medical researchers focus more on developing reliable laboratory diagnosis, quicker methods of identifying the LASV and drug/vaccine formulation, the natural scientist (Bio-mathematicians) on the other hand focuses on modeling the dynamic transmission and controls among the various hosts of the LASV. This paper presents a mathematical model that tracks the transmission dynamics of Lassa fever in two different but complimentary host; human host and rat host. The model incorporates a death infectious human compartment capable of infecting susceptible population. The model analysis, basic reproduction number, existence of endemic equilibrium and bifurcation analysis was analyzed. It was established that the disease-free equilibrium point is stable when the reproduction number, $\mathrm{R}_{0}<1$ and the disease dies out. Numerical simulation was carried out with parametized data for Ebonyi State, Eastern Nigeria. The numerical simulation reveals that sensitization of susceptible population, quarantined of exposed humans and isolation of infectious humans, the practice of best international safety measures among health care workers, establishment of more Lassa fever diagnostic centres and precautionary burial practices remains the best control measures in the dynamic transmission of Lassa fever.
\end{abstract}

Keywords: Lassa Fever, Quarantine, Isolation, Basic Reproduction Number, Bifurcation, Endemic

\section{Introduction}

Lassa fever (LF) is a zoonotic viral hemorrhagic fever (VHF) cause by Lassa virus (LASV). The LASV belongs to the order Bunyavirales, the family Arenaviridae and genus Mammarenavirus. The primary host is the rodent multimammate rat (Mastomysnatalensis) which also spread the virus [9]. Once the rodent is infected, it shows no symptom, but excretes the virus through its feces and urines for its life time [26]. Humans contact the virus through direct contact with the infected rodent, rodents' excreta, contaminated objects, inhalation of contaminated aerosols, swallowing of the virus and contact with body fluids of infectious humans. There is currently no study that has proven the presence of LASV in breast milk, but excretion of LASV in semen has been observed three months postinfection [24] and high levels of viremia in breast milk suggest that transmission may occur via breastfeeding [10]. The signs and symptoms of LF are mostly non-specific, often mistaken for other common febrile illnesses such as malaria and Typhoid $[5,27]$. This has no doubt contributed to the high person-to-person transmission especially among healthcare workers (HCWs). One of the dreaded realities about the transmission of this disease is the fact that even the corpse of an infected human can transmit the disease [7]. 
Lassa fever is endemic in Western African countries such as Nigeria, Sierra Leone, Guinea and Liberia. It recently affected Mali and Ivory Coast [9, 13]. Approximately 100, 000 to 300,000 clinical infections and 5,000 deaths per year are estimated to have occurred in the endemic regions [5]. Despite the fact that Lassa fever was first discovered in 1969 from Lassa, a town in Borno state of northern Nigeria, it is regrettable that after 50 years of the disease's documented history, Nigeria still struggles with deadly outbreaks all through the year. According to [15], Nigeria experienced the largest outbreak of Lassa fever ever recorded in any part of the world in the year 2018. From January $1^{\text {st }}$ to December $31^{\text {st }}, 2018$, the country reported 3,498 suspected cases of Lassa fever in 23 states with at least 1 confirm case across 93 Local Government Areas (LGAs). Among the 633 confirmed cases, $80 \%$ are all from the southern region of the country as follows; Edo (44\%), Ondo (25\%) and Ebonyi (11\%) states. A total of 171 deaths with case fatality of $27 \%$ has been recorded. A total of 45 health HCWs were affected; Ebonyi state (16), Edo (15), Ondo (8) Kogi (2), Nasarawa (1), Taraba (1) and Abia (2). Of the HCWs affected 10 died; Ebonyi State (5), Kogi (1), Abia (1), Ondo (2) and Edo (1) (NCDC, 2018). Deaths in 2019 may outnumber the previous year if the current rate of case detection is sustained. According to [16], between January $1^{\text {st }}$ to September $19^{\text {th }}, 2019$ a total of 3, 728 suspected cases of Lassa fever in 23 states have beenrecorded with at least 694 confirm cases across 83 LGAs. Among the 694 confirmed cases, 19 are HCWs. A total of 149 deaths with case fatality of $21.5 \%$ were also recorded. Out of the 149 deaths, 19 were HCWs with Edo (6), Ebonyi (2), Ondo (4) while Enugu, Rivers, Bauchi, Benue, Delta, Plateau and Kebbi states recorded (1) each (NCDC, 2019). One of the possible reasons for high outbreaks in Nigeria (especially Eastern and Southern Nigeria), maybe attributed to ignorance and fictitious beliefs among the populace on preference of traditional medication when sick rather than orthodox medication where they will be medically examine first, unprotected burying/handling of corpse by morticians or relations, poor medical facilities in the hospitals etc. Unfortunately, administration of ribavirin, the only antiviral medicine for the treatment of LF is only effective when given in the early stage of the disease, preferably within the first six days after onset [27].

In the wake of the recent outbreaks of the virus in Nigeria between 2008 and 2019, it is clear that Lassa fever has become a serious threat to public health in Nigeria. with Ebonyi State as the most affected state in the Southeast geopolitical zone while Edo State and Ogun State in the South-south and Southwest geopolitical zones of the country respectively (see Figure 10 and Figure 11). This has activated interventional measures coming from both the government and scholars. The government through the Nigeria Centre for Disease Control (NCDC) and other sister agencies has activated an emergency response by establishing management centres which operates in association with specialist teaching hospitals in the endemic states. Also rapid response teams were constituted to work with states in response co-ordination, contact tracing, case management, risk communication, and strengthening infection prevention and control practices. Scholars on the other hand are approaching the menace from two broad but complimentary aspects of sciences namely; the medical sciences and the natural sciences. While the medical researchers focus more on developing reliable laboratory diagnosis, quicker methods of identifying the LASV and drug/vaccine formulation $[6,11$, $12,14,23,22,28]$, the natural scientist (Bio-mathematicians) on the other hand focuses on modeling the dynamic transmission and controls among the various hosts of the LASV.

Various theoretical studies have been carried out on mathematical modeling of Lassa fever transmission dynamics, focusing on a number of different aspects. In the work of [26], they developed a mathematical model for the transmission dynamics of the Lassa fever virus infection by splitting the infectious human population into symptomatic and asymptomatic infectious and assumed that the animal reservoirs do not recover once infected. Their model revealed that, the disease becomes endemic in the rodents population and also do not die out of the human population over time without controlling the growth of the rodents population, by preventing animal-human transmissions and improvement on the human recovery rates. Their model also reveals that the disease will be wiped out of the hosts populations over time. Also [8] presented a mathematical model that tracks the transmission dynamics of Lassa fever in a two-interacting human host and rodent vector populations. The model incorporates a non-drug compliance rate in the parameters for the human population. It revealed that intervention strategies need to be focused on treatment and reduction on the contact between the rodent vector and human host. Since the nondrug compliance rate of infectious human hosts causes reappearance of symptoms after a symptom free period, there is need to increase caution which will reduces the number of infectious human hosts who do not comply with drug. He also suggests the need for isolation of the infectious human hosts in order to reduce the spread of Lassa fever. In the work of [17] they formulated a new mathematical model with focuses on the human and rodent population using maximum principle of theorem to establish the positivity and boundedness of the solution. Their study still reveals that maintaining hygienic environment and control of the rodent activities remain the best way of stamping the control of LF. While [26] in their paper presented a deterministic model of Lassa fever transmission with quarantine and permanent immunity. The existence and uniqueness of the solution were also proved. Their model was globally asymptotic, which implies that the disease will be wiped out irrespective of the initial population size. In the work of [19] proposed in their model the need to develop a model that will incorporate the effects of vaccination on a subset of the target population. However in the absent of vaccine, they proposed in the interim the quarantine of infected persons and control of rodent activity as the best prevention strategies and also their model coupled to a population of rat for the transmission of 
Lassa fever disease. They calculated the basic reproduction number for their model and gave conditions for disease outbreak. In [18] they developed a Susceptible-InfectedRecovery (SIR) model for controlling Lassa fever transmission in Northern part of Edo state, Nigeria. They advocated for health policies that will keep the basic reproduction number, $R_{0}$ below 1 , thereby keeping the transmission of the disease under control. Furthermore, [3] developed a mathematical model for Lassa fever where they divided the human population into susceptible human and the infectious human and the reservoir population into infant and the adult reservoir and represented the virus in the environment by V. They explained that the virus compartment is generated from the urine and feces of infected human and adult reservoirs. In the work of [21], they developed a Lassa fever model using the sex structure approach. Their model represented the transmission dynamics of the Lassa fever disease using a set of ordinary differential equations. Their model had the following assumptions: Susceptible individuals, male/female can be infected through interaction with the active Reservoir (Mastomys Natelensis), and through sexual interaction with opposite sex. Two major controls were considered, the use of condom to reduce contact through sexual interaction and the use of pesticide/rat poison to kill the natural Reservoir.

Thus, based on the literatures that the authors were able to review, no mathematical model for Lassa fever has been developed which incorporated infectious death humans as a compartment and or parametized for Ebonyi state, being the most affected state in South-east geopolitical zone of Nigeria. In this research, we will formulate a mathematical model that will incorporate the death infectious human compartment and other suggestions of the reviewed literatures for the control and transmission dynamics of Lassa fever. The model will be parameterized for Ebonyi state of Nigeria being the state with high seasonal outbreaks in the whole of the Southeast geopolitical zone of the country to reflect a LASV endemic region in Nigeria.

\section{Model Formulations}

In this section, we present the formulation of a deterministic model for Lassa fever. First, we state the model assumptions, model description, the schematic diagram, the model parameters and state variables and the model equations.

\subsection{Model Assumptions}

The model is formulated based on the following assumptions;

1. Deceased infectious humans can still infect susceptible humans before and during funerals. This assumption is motivated by the case of an infectious corpse of a LF individual that infects a mortician/undertaker in Germany and also based on the Nigerian burial practices (e.g. washing of deceased individuals) during burial ceremonies [7].
2. There is homogeneous mixing of members of the population under consideration.

3. We assume that there is a vital dynamics because of the continuous yearly outbreaks of Lassa fever in the various geopolitical zones of the country (Nigeria). Thus, during this relatively long period of time, there might be new births or inflow of susceptible individuals from other/surrounded places as well as natural deaths, which allow a demographic process to take place.

4. Infection is acquired either via direct contact with rodent or via interaction with infectious human or rodent contaminants in the environment.

5. In order for an individual to become infectious, he/she must pass through the latent stage.

\subsection{Model Description}

In our model, the host population is divided into two; the rodent (rat) reservoir and the human population. For the rodent reservoir, the total rodent population, $N_{R}(t)$, at time, $t$, is divided into subpopulations/compartments namely Susceptible, $S_{R}(t)$, Exposed, $E_{R}(t)$, and Infectious, $I_{R}(t)$, i.e. the rodent population at any given time, $t$, is given by

$$
N_{R}(t)=S_{R}(t)+E_{R}(t)+I_{R}(t) .
$$

Rodents are recruited into the susceptible class, $S_{R}(t)$, at a constant rate, $\Lambda_{R}$, through birth or immigration of the rodent and they exit either through natural death at the rate, $\mu_{R}$, human control measures/hunting by other predators rate, $\rho_{R}$, or by infection induced by the disease with force of infection, $\lambda_{R}$. i.e.

$$
\frac{d S_{R}}{d t}=\Lambda_{R}-\lambda_{R} S_{R}-\mu_{R} S_{R}-\rho_{R} S_{R}
$$

Where

$$
\lambda_{R}=\beta_{R} \frac{I_{R}}{N_{R}}
$$

and $\beta_{R}$ is the effective contact rate between the infectious rodent and susceptible rodent.

The exposed rodent class, $E_{R}(t)$, gains population through infection induced by the disease with the force of infection, $\lambda_{R}$, and exits either through natural death rate, $\mu_{R}$, human control measures/hunting by other predators rate, $\rho_{R}$, or by progression rate, $\sigma_{R}$, into the Infectious rodent class, $I_{R}(t)$, i.e.

$$
\frac{d E_{R}}{d t}=\lambda_{R} S_{R}-\mu_{R} E_{R}-\rho_{R} E_{R}-\sigma_{R} E_{R}
$$

The infectious rodent class, $I_{R}(t)$, gains population from the progression from exposed class at rate, $\sigma_{R}$, and they exit either through natural death rate, $\mu_{R}$, or from human control measures/hunting by other predators rate, $\rho_{R}$, since the rodentscannot be killed by the disease, i.e.

$$
\frac{\mathrm{dI}}{\mathrm{dt}}=\sigma_{R} \mathrm{E}_{\mathrm{R}}-\mu_{\mathrm{R}} \mathrm{I}_{\mathrm{R}}-\rho_{\mathrm{R}} \mathrm{I}_{\mathrm{R}}
$$


For the human population, the total human population, $N_{H}(t)$, at time, $t$, is divided into subpopulations/compartments; Susceptible, $S_{H}(t)$, Exposed, $E_{H}(t)$, Quarantined, $E_{T H}(t)$, Exposed but not quarantined, $E_{N H}(t)$, Infectious, $I_{H}(t)$, Infectious and Isolated, $I_{Q H}(t)$, and Infectious Human Corpse or Dead infectious human, $D_{H}(t)$. In the human population, we incorporates two control measures; quarantine, (i.e. treatment of a known latent infected person without confinement/restriction of movement and interaction with susceptible human), and Isolation (i.e. isolation or confinement of an infectious person from interacting with susceptible human while receiving intensive medical care). The human population at any given time, $t$, is given by

$$
\mathrm{N}_{\mathrm{H}}(t)=\mathrm{S}_{\mathrm{H}}(t)+\mathrm{E}_{\mathrm{H}}(t)+\mathrm{E}_{\mathrm{TH}}(t)+\mathrm{E}_{\mathrm{NH}}(t)+\mathrm{I}_{\mathrm{H}}(t)+\mathrm{I}_{\mathrm{HQ}}(t)
$$

Susceptible humans, $S_{H}(t)$, are recruited into compartment at a constant rate, $\Lambda_{H}$, through birth or immigration of the human, and from those that recovered from quarantine and isolation at rates, $\rho_{3}$ and $\rho_{6}$, respectively. Susceptible human exit either through natural death rate, $\mu_{H}$, or by infection induced by the disease with force of infection, $\lambda_{H}$, i.e. $\frac{\mathrm{dS}_{\mathrm{H}}}{\mathrm{dt}}=$ $\Lambda_{\mathrm{H}}-\lambda_{\mathrm{H}} S_{\mathrm{H}}-\mu_{\mathrm{H}} S_{\mathrm{H}}+\rho_{3} \mathrm{E}_{\mathrm{TH}}+\rho_{6} \mathrm{I}_{\mathrm{QH}}$ where

$$
\lambda_{\mathrm{H}}=\beta_{H} \frac{I_{R}}{N_{R}}+\frac{\beta_{1} I_{Q H}+\beta_{2} I_{H}+\beta_{3} D}{N_{H}}
$$

and $\beta_{H}$, is the effective contact rate between theinfectious rodent or its contaminants and susceptible human, while, $\beta_{1}, \beta_{2}$ and $\beta_{3}$, are the effective contact rates between theinfectious, isolated, dead infectious humans and susceptible human respectively.

The exposed human class, $E_{H}(t)$, gains population through infection induced by the disease with the force of infection, $\lambda_{H}$, and a proportion, $(1-\varphi)$, exits due to enlightenment campaign/sensitization and are quarantined at rate, $\rho_{2}$, (especially among Health Care Workers who might have realized that they have come in contact with a confirm infectious person or family members of a confirmed infectious human) while the remaining proportion, $\varphi \epsilon[0,1]$, of the Exposed human will progress to the exposed but not treated class, $E_{N H}(t)$, at the rate, $\rho_{1}$, or some exits through natural death rate, $\mu_{H}$, i.e.

$$
\frac{d E_{H}}{d t}=\lambda_{H} S_{H}-(1-\varphi) \rho_{2} E_{H}-\varphi \rho_{1} E_{H}-\mu_{H} E_{H}
$$

The Exposed but not treated class, $E_{N T}$, gains population from the proportion, $\varphi$, of exposed human that are not quarantined at a rate, $\rho_{1}$, and exits either through natural death rate, $\mu_{H}$, or through progression to infectious class at a rate, $\rho_{5}$, i.e. $\frac{d \mathrm{E}_{\mathrm{NT}}}{\mathrm{dt}}=\varphi \rho_{1} \mathrm{E}_{\mathrm{H}}-\rho_{5} \mathrm{E}_{\mathrm{NH}}-\mu_{\mathrm{H}} \mathrm{E}_{\mathrm{NH}}$

The quarantined class, $E_{T H}$, gains population from the proportion, $(1-\varphi)$, of the exposed human at a rate, $\rho_{2}$, and exits either through natural death rate, $\mu_{H}$, or through returning back to susceptible class at a rate, $\rho_{3}$, after spending 21 days of the incubation period of Lassa in the quarantine class without symptoms or progression to isolated human at a rate, $\rho_{4}$, if anyone develop symptoms, i.e.

$$
\frac{d E_{T H}}{d t}=(1-\varphi) \rho_{2} E_{H}-\rho_{3} E_{T H}-\rho_{4} E_{T H}-\mu_{H} E_{T H} .
$$

The infectious human compartment, $I_{H}$, gain population from progression from, $E_{N H}$, to infectious class at a rate, $\rho_{5}$, and exits either through natural death rate, $\mu_{H}$, or through the rate, $\rho_{7}$, which infectious human areisolated for intensive treatment, or diedwith disease induced death rate, $d_{1}$, i.e.

$$
\frac{d I_{H}}{d t}=\rho_{5} E_{N H}-\rho_{7} I_{H}-d_{1} I_{H}-\mu_{H} I_{H} .
$$

The Isolated compartment, $I_{Q H}$, gains population from those quarantined and infectious human that are isolated at rates, $\rho_{4}$, and $\rho_{7}$, respectively and exits either through natural death rate of human, $\mu_{H}$, or through the rate, $\rho_{6}$, at which isolate individuals get treated and moves back to susceptible class after receiving intense treatment/improved immunity or die with disease induced death rate, $d_{2}$, i.e.

$$
\frac{\mathrm{dI}_{\mathrm{QH}}}{\mathrm{dt}}=\rho_{7} \mathrm{I}_{\mathrm{H}}+\rho_{4} \mathrm{E}_{\mathrm{TH}}-\rho_{6} \mathrm{I}_{\mathrm{QH}}-\mu_{\mathrm{H}} \mathrm{I}_{\mathrm{QH}}-\mathrm{d}_{2} \mathrm{I}_{\mathrm{QH}} \cdot
$$

Infectious Human Corpse or Death infectious human compartment, $D_{H}$, can infects susceptible human (especially morticians/undertakers). It gains population from the disease induced rates for infectious and isolated humans at rates, $d_{1}$ and $d_{2}$, respectively and exits through proper buried and carefulness of infectious human corpse at the rate, $\gamma$, i.e. $\frac{d D_{H}}{d t}=d_{2} I_{Q H}+d_{1} I_{H}-\gamma D_{H}$.

The model state variables and model parameters are represented and described in Table 1 and Table 2 respectively. The model flow diagram is given in Figure 1.

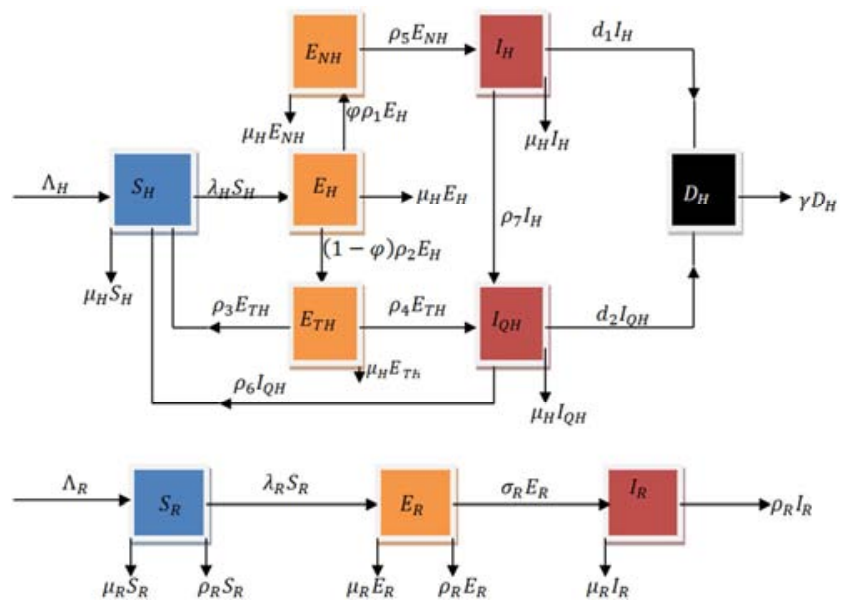

Figure 1. Systematic diagram of Lassa fever model.

Table 1. State Variables of the Model.

\begin{tabular}{ll}
\hline Variables & Description \\
\hline$N_{R}(t)$ & Total number of rodent population at time, $t$, \\
$S_{R}(t)$ & Total number of Susceptible rodent population at time, $t$, \\
\hline
\end{tabular}




\begin{tabular}{ll}
\hline Variables & Description \\
\hline$E_{R}(t)$ & Total number of Exposed rodent population at time, $t$, \\
$I_{R}(t)$ & Total number of Infectious rodent population at time, $t$, \\
$N_{H}(t)$ & Total number of human population at time, $t$, \\
$S_{H}(t)$ & Total number of Susceptible human population at time, $t$, \\
$E_{H}(t)$ & Total number of Exposed human population at time, $t$, \\
$E_{T H}(t)$ & Total number of quarantined human population at time, $t$, \\
$E_{N H}(t)$ & Total number of Exposed but not treated population at time, $t$, \\
$I_{H}(t)$ & Total number of infectious human population at time, $t$, \\
$I_{Q H}(t)$ & Total number of Isolated human population at time, $t$, \\
$D_{H}(t)$ & Total number of Infectious Human Corpse yet to be buried population at time, $t$, \\
\hline
\end{tabular}

\subsection{Model Equation}

From the schematic diagram, the following set of non-linear ODE's are derived

$$
\begin{aligned}
& \frac{d S_{H}}{d t}=\Lambda_{H}-\lambda_{H} S_{H}-\mu_{H} S_{H}+\rho_{3} E_{T H}+\rho_{6} I_{Q H} \\
& \frac{\mathrm{dE}_{\mathrm{H}}}{\mathrm{dt}}=\lambda_{\mathrm{H}} \mathrm{S}_{\mathrm{H}}-(1-\varphi) \rho_{2} \mathrm{E}_{\mathrm{H}}-\varphi \rho_{1} \mathrm{E}_{\mathrm{H}}-\mu_{\mathrm{H}} \mathrm{E}_{\mathrm{H}} \\
& \frac{d E_{T H}}{d t}=(1-\varphi) \rho_{2} E_{H}-\rho_{3} E_{T H}-\rho_{4} E_{T H}-\mu_{H} E_{H} \\
& \frac{\mathrm{dE}_{\mathrm{NT}}}{\mathrm{dt}}=\varphi \rho_{1} \mathrm{E}_{\mathrm{H}}-\rho_{5} \mathrm{E}_{\mathrm{NH}}-\mu_{\mathrm{H}} \mathrm{E}_{\mathrm{NH}} \\
& \frac{\mathrm{dI}_{\mathrm{H}}}{\mathrm{dt}}=\rho_{5} \mathrm{E}_{\mathrm{NH}}-\rho_{7} \mathrm{I}_{\mathrm{H}}-\mathrm{d}_{1} \mathrm{I}_{\mathrm{H}}-\mu_{\mathrm{H}} \mathrm{I}_{\mathrm{H}} \\
& \frac{\mathrm{dI}_{\mathrm{QH}}}{\mathrm{dt}}=\rho_{7} \mathrm{I}_{\mathrm{H}}+\rho_{4} \mathrm{E}_{\mathrm{TH}}-\rho_{6} \mathrm{I}_{\mathrm{QH}}-\mu_{\mathrm{H}} \mathrm{I}_{\mathrm{QH}}-\mathrm{d}_{2} \mathrm{I}_{\mathrm{QH}} \\
& \frac{\mathrm{dD}_{\mathrm{H}}}{\mathrm{dt}}=\mathrm{d}_{2} \mathrm{I}_{\mathrm{QH}}+\mathrm{d}_{1} \mathrm{I}_{\mathrm{H}}-\gamma \mathrm{D}_{\mathrm{H}} \\
& \frac{d S_{R}}{d t}=\Lambda_{R}-\lambda_{R} S_{R}-\mu_{R} S_{R}-\rho_{R} S_{R} \\
& \frac{\mathrm{dE}_{\mathrm{R}}}{\mathrm{dt}}=\lambda_{\mathrm{R}} \mathrm{S}_{\mathrm{R}}-\mu_{\mathrm{R}} \mathrm{E}_{\mathrm{R}}-\rho_{\mathrm{R}} \mathrm{E}_{\mathrm{R}}-\sigma_{R} \mathrm{E}_{\mathrm{R}} \\
& \frac{\mathrm{dI}}{\mathrm{dt}}=\sigma_{R} \mathrm{E}_{\mathrm{R}}-\mu_{\mathrm{R}} \mathrm{I}_{\mathrm{R}}-\rho_{\mathrm{R}} \mathrm{I}_{\mathrm{R}}
\end{aligned}
$$

subject to the initial conditions, $\mathrm{S}_{\mathrm{H}}(0)>0, \mathrm{E}_{\mathrm{H}}(0) \geq$ $0, \mathrm{E}_{\mathrm{TH}}(0) \geq 0, \mathrm{E}_{\mathrm{NH}}(0) \geq 0, \mathrm{I}_{\mathrm{H}}(0) \geq 0, \mathrm{I}_{\mathrm{HQ}}(0) \geq 0, \mathrm{D}_{\mathrm{H}}(0) \geq$ $0, \mathrm{~S}_{\mathrm{R}}(0)>0, \mathrm{E}_{\mathrm{R}}(0) \geq 0$ andI $_{\mathrm{R}}(0) \geq 0$ and the force of infections for the rodent and human, $\lambda_{\mathrm{R}}$ and $\lambda_{\mathrm{H}}$, are defined in equations (2) and (4) respectively.

\section{Model Analysis}

The model equations (5) is analyzed qualitatively to get insights into its dynamical features for better understanding of the impact of the various control strategies on the transmission dynamics of Lassa fever.

\subsection{Well-Posedness of the Model Equations}

We establish the well-posedness of the model by proving the positivity and boundedness of the solutions of the model with the non-negative initial solution for all time.

Lemma 1: The LASV model (5) is well-posed and valid in the region.

$$
\Omega=\left\{S_{H}(t), E_{H}(t), E_{T H}(t), E_{N H}(t), I_{H}(t), I_{Q H}(t), D_{H}(t), S_{R}(t), E_{R}(t), I_{R}(t) \in \mathbb{R}_{+}^{10}: N_{H}(t) \leq \frac{\Lambda_{H}}{\mu_{H}}, D_{H}(t) \leq \frac{\left(d_{1}+d_{2}\right) \Lambda_{H}}{\mu_{H} r}, N_{R}(t) \leq \frac{\Lambda_{R}}{\mu_{R}}\right\}
$$

\section{PROOF:}

The proof is provided in two steps.

Step1 (Proof of the Positivity of the Solutions of the Model)

Let the set of initial solution be

$$
\left\{S_{H}(0), E_{H}(0), E_{T H}(0), E_{N H}(0), I_{H}(0), I_{Q H}(0), D_{H}(0), S_{R}(0), E_{R}(0), I_{R}(0)\right\} \in \Omega .
$$

We assume that the set of initial solutions,

$$
\left(\begin{array}{c}
S(0), E(0), E_{T}(0), I(0), I_{N}(0), I_{T}(0), R(0) S_{H}(0), E_{H}(0), E_{T H}(0), E_{N H}(0), I_{H}(0), I_{Q H}(0), D_{H}(0), \\
S_{R}(0), E_{R}(0), I_{R}(0)
\end{array}\right) \geq 0 .
$$

Then, the first equation of (5) can be written as

$$
\frac{d \mathrm{~S}_{H}}{d t}=\Lambda_{H}-\lambda_{H}(t) \mathrm{S}_{H}-\mu_{H} \mathrm{~S}_{H}+\rho_{3} E_{T H}(t)+\rho_{6} I_{Q H}(t) .
$$




$$
\frac{d \mathrm{~S}_{H}}{d t} \geq \Lambda_{H}-\beta_{h}(t) \mathrm{S}_{H} .
$$

where $\beta_{h}(t)=\lambda_{H}(t)+\mu_{H}$ and $\lambda_{H}(t)=\frac{\beta_{H} I_{R}}{\mathrm{~N}_{R}}+\frac{\beta_{1} I_{H}+\beta_{2} I_{Q H}+\beta_{3} D_{H}}{\mathrm{~N}_{H}}$.

Equation (4) is a linear first order ordinary differential equation in $\mathrm{S}_{H}(t)$ with the solution

$$
\mathrm{S}_{H}(t)=\mathrm{S}_{H}(0) \exp \left(\int_{0}^{t}-\beta_{h}(s) d s\right)+\exp \left(\int_{0}^{t}-\beta_{h}(s) d s\right) \times \int_{0}^{t} \Lambda_{H} \exp \left(\int_{0}^{u} \beta_{h}(\omega) d \omega\right) d u \geq 0
$$

Hence, $\mathrm{S}_{H}(t) \geq 0 \forall \mathrm{t} \geq 0$.

In a similar way, the remaining state variables are obtained such that

$$
\left.\begin{array}{c}
\mathrm{E}_{H}(t) \geq \mathrm{E}_{H}(0) \exp \left(-\left(\mu_{H}+\omega \rho_{1}+(1-\omega) \rho_{2}\right) \geq 0, \forall \mathrm{t} \geq 0\right. \\
E_{T H}(t) \geq E_{T H}(0) \exp \left(-\left(\mu_{H}+\rho_{3}+\rho_{4}\right)\right) \geq 0, \forall \mathrm{t} \geq 0 \\
E_{N H}(t) \geq E_{N H}(0) \exp \left(-\left(\mu_{H}+\rho_{5}\right)\right) \geq 0, \forall \mathrm{t} \geq 0 \\
\mathrm{I}_{H}(t) \geq \mathrm{I}_{H}(0) \exp \left(-\left(\mu_{H}+\rho_{7}+d_{1}\right)\right) \geq 0, \forall \mathrm{t} \geq 0 \\
I_{Q H}(t) \geq I_{Q H}(0) \exp \left(-\left(\mu_{H}+\rho_{6}+d_{2}\right)\right) \geq 0, \forall \mathrm{t} \geq 0 \\
D_{H}(t) \geq D_{H}(0) \exp (-\Upsilon) \geq 0, \forall \mathrm{t} \geq 0
\end{array}\right\}
$$

For the rodent again,

$$
\mathrm{S}_{R}(t)=\mathrm{S}_{R}(0) \exp \left(\int_{0}^{t}-\beta_{r}(s) d s\right)+\exp \left(\int_{0}^{t}-\beta_{r}(s) d s\right) \times \int_{0}^{t} \Lambda_{R} \exp \left(\int_{0}^{u} \beta_{r}(\omega) d \omega\right) d u \geq 0, \forall \mathrm{t} \geq 0,
$$

In a similar way,

$$
\left.\begin{array}{c}
\mathrm{E}_{R}(t) \geq \mathrm{E}_{R}(0) \exp \left(-\left(\mu_{R}+\rho_{\mathrm{R}}+\sigma_{R}\right) \geq 0, \forall \mathrm{t} \geq 0\right. \\
\mathrm{I}_{R}(t) \geq \mathrm{I}_{R}(0) \exp \left(-\left(\mu_{R}+\rho_{\mathrm{R}}\right)\right) \geq 0, \forall \mathrm{t} \geq 0
\end{array}\right\}
$$

Where

$$
\beta_{r}(t)=\lambda_{R}(t)+\mu_{H} \text { and } \lambda_{H}(t)=\frac{\beta_{R} I_{R}}{\mathrm{~N}_{R}} .
$$

Hence, the solution set $\left\{S_{H}(t), E_{H}(t), E_{T H}(t), E_{N H}(t), I_{H}(t), I_{Q H}(t), D_{H}(t), S_{R}(t), E_{R}(t), I_{R}(t)\right\}$ of the LASV model is positive for all $t \geq 0$ since exponential functions are positive functions based on equations (5) - (7).

Step 2 (Prove of the Boundedness of the Solution)

The active human, dead human and the rodent populations satisfy the inequalities

$$
N_{H}(t) \leq \frac{\Lambda_{H}}{\mu_{H}}, D_{H}(t) \leq \frac{\left(d_{1}+d_{2}\right) \Lambda_{H}}{\mu_{H} \Upsilon} \text { and } N_{R}(t) \leq \frac{\Lambda_{R}}{\mu_{R}}
$$

based on the assumption that the initial conditions for LASV model satisfy

$$
N_{H}(0) \leq \frac{\Lambda_{H}}{\mu_{H}}, D_{H}(0) \leq \frac{\left(d_{1}+d_{2}\right) \Lambda_{H}}{\mu_{H} \Upsilon} \text { and } N_{R}(0) \leq \frac{\Lambda_{R}}{\mu_{R}}
$$

Proof:

The total active human population at any time, $\mathrm{t}$, can be determined by

$$
N_{H}(t)=S_{H}(t)+E_{H}(t)+E_{T H}(t)+E_{N H}(t)+I_{H}(t)+I_{Q H}(t) .
$$

Also, the total rodent population at any time, $t$, can be determined by

$$
N_{R}(t)=S_{R}(t)+E_{R}(t)+I_{R}(t) .
$$

So, the time derivatives, $\frac{d N_{H}}{d t}$ and $\frac{d N_{R}}{d t}$, along solutions of thesystem are obtained as

$$
\frac{d N_{H}}{d t}=\Lambda_{H}-\mu_{H} N_{H}-d_{1} I_{H}-d_{2} I_{Q H} \leq \Lambda_{H}-\mu_{H} N_{H}
$$

and

$$
\frac{d N_{R}}{d t}=\Lambda_{R}-\left(\mu_{R}+\rho_{\mathrm{R}}\right) N_{H} \leq \Lambda_{R}-\mu_{R} N_{R}
$$


Here, $d_{1}, d_{2}$ and $\rho_{R}$, are negligible. Then, applying the Gronwall's inequality gives

$$
N_{H}(t) \leq \frac{\Lambda_{H}}{\mu_{H}}+\left(N_{H}(0)-\frac{\Lambda_{H}}{\mu_{H}}\right) e^{-\mu_{H} t} \text { whenever } N_{H}(0) \leq \frac{\Lambda_{H}}{\mu_{H}}
$$

and

$$
N_{R}(t) \leq \frac{\Lambda_{R}}{\mu_{R}}+\left(N_{R}(0)-\frac{\Lambda_{R}}{\mu_{R}}\right) e^{-\mu_{R} t} \text { whenever } N_{R}(0) \leq \frac{\Lambda_{R}}{\mu_{R}}
$$

So, taking the limit as $t \rightarrow \infty$ yields $N_{H}(t) \leq \frac{\Lambda_{H}}{\mu_{H}}$ and $N_{R}(t) \leq \frac{\Lambda_{R}}{\mu_{R}}$.

It is natural that $I_{H} \leq N_{H}$ and $I_{Q H} \leq N_{H}$.

So that,

$$
\frac{d D_{H}}{d t} \leq\left(d_{1}+d_{2}\right) N_{H}-\Upsilon D_{H}=\left(d_{1}+d_{2}\right) \frac{\Lambda_{H}}{\mu_{H}}-\Upsilon D_{H}
$$

where $N_{H}(t) \leq \frac{\Lambda_{H}}{\mu_{H}}$.

Again, applying the Gronwall's inequality to (8) yields

$$
D_{H}(t) \leq \frac{\left(d_{1}+d_{2}\right) \Lambda_{H}}{\mu_{H} \Upsilon}+\left(D_{H}(0)-\frac{\left(d_{1}+d_{2}\right) \Lambda_{H}}{\mu_{H} \Upsilon}\right) e^{-\Upsilon t} \text { whenever } D_{H}(0) \leq \frac{\left(d_{1}+d_{2}\right) \Lambda_{H}}{\mu_{H} \Upsilon} .
$$

This gives $D_{H}(t) \leq \frac{\left(d_{1}+d_{2}\right) \Lambda_{H}}{\mu_{H} \Upsilon}$ ast $\rightarrow \infty$.

This shows that the feasible region for the model exists and is bounded by

$$
N_{H}(t) \leq \frac{\Lambda_{H}}{\mu_{H}}, D_{H}(t) \leq \frac{\left(d_{1}+d_{2}\right) \Lambda_{H}}{\mu_{H} \Upsilon} \text { and } N_{R}(t) \leq \frac{\Lambda_{R}}{\mu_{R}} .
$$

It means that all the solutions of the LASV model are nonnegative in $\Omega$ for any time, $t>0$.

\subsection{Existences of Equilibria}

The disease free-equilibrium, $\mathrm{E}_{0}$, of the model system (5) is denoted as

$$
\mathrm{E}_{0}=\left(\mathrm{S}_{\mathrm{H}}^{0}, \mathrm{E}_{\mathrm{TH}}^{0}, \mathrm{E}_{\mathrm{NH}}^{0}, \mathrm{I}_{\mathrm{H}}^{0}, \mathrm{I}_{\mathrm{QH}}^{0}, \mathrm{D}_{\mathrm{H}}^{0}, \mathrm{~S}_{\mathrm{R}}^{0}, \mathrm{E}_{\mathrm{R}}^{0}, \mathrm{I}_{\mathrm{R}}^{0}\right)
$$

and is obtained in the absence of infection (i.e. $I_{H}=0$ ).

Setting the right hand side of the system (5) equal to zero and solve simultaneously, we get the disease-free equilibrium state as

$$
\mathrm{E}_{0}=\left(\frac{\Lambda_{\mathrm{H}}}{\mu_{\mathrm{H}}}, 0,0,0,0,0,0, \frac{\Lambda_{\mathrm{R}}}{\mu_{\mathrm{R}}+\rho_{\mathrm{R}}}, 0,0\right) .
$$

\subsection{The Basic Reproduction Number $R_{0}$}

The basic reproduction number, $R_{0}$, is used in determining the transmission capability of the disease. It is viewed as the quantity of secondary diseases delivered by a primary case of an infection in a population that is completely susceptible. It can be estimated from the quantity of secondary infections when a disease is introduced into an absolutely susceptible population. $R_{0}$ is a threshold quantity that decides if a pathogen can hold on in a population or not. If $R_{0}<1$, then the disease will die out with time in the population, otherwise if $R_{0}>1$ it will leads to endemic state in the population, and it is also important for evaluating control alternatives.

Using the next generation approach to compute the basic reproduction number, $R_{0}$, it is defined to be largest eigenvalue or spectral radius of $\mathrm{GU}^{-1}$ with the associated matrix $F$ (i.e. the rate of appearance of new infection in the susceptible compartments) and matrix $V$ (i.e. the transfer of infections from infected compartments to another) as shown below;

$$
\mathrm{F}=\left[\begin{array}{c}
\frac{\beta_{\mathrm{H}} \mathrm{I}_{\mathrm{R}} \mathrm{S}_{\mathrm{H}}}{\mathrm{N}_{\mathrm{R}}}+\frac{\left(\beta_{1} \mathrm{I}_{\mathrm{H}}+\beta_{2} \mathrm{I}_{\mathrm{QH}}+\beta_{3} \mathrm{D}\right) \mathrm{S}_{\mathrm{H}}}{\mathrm{N}_{\mathrm{H}}} \\
0 \\
0 \\
0 \\
0 \\
\frac{\beta_{\mathrm{R}} \mathrm{I}_{\mathrm{R}} \mathrm{S}_{\mathrm{R}}}{\mathrm{N}_{\mathrm{R}}} \\
0
\end{array}\right], V=\left[\begin{array}{c}
\mathrm{fE}_{\mathrm{H}} \\
-(1-\varphi) \rho_{2} \mathrm{E}_{\mathrm{H}}+\mathrm{gE}_{\mathrm{TH}} \\
-\varphi \rho_{1} \mathrm{E}_{\mathrm{H}}+\mathrm{h} \mathrm{E}_{\mathrm{NH}} \\
-\rho_{5} \mathrm{E}_{\mathrm{NH}}+\mathrm{pI} \mathrm{I}_{\mathrm{H}} \\
-\rho_{7} \mathrm{I}_{\mathrm{H}}-\rho_{4} \mathrm{E}_{\mathrm{TH}}+\mathrm{qI} \mathrm{I}_{\mathrm{QH}} \\
-\mathrm{d}_{2} \mathrm{I}_{\mathrm{QH}}-\mathrm{d}_{1} \mathrm{I}_{\mathrm{H}}+\gamma \mathrm{D}_{\mathrm{H}} \\
r \mathrm{E}_{\mathrm{R}} \\
-\sigma_{R} \mathrm{E}_{\mathrm{R}}+\mathrm{sI}_{\mathrm{R}}
\end{array}\right]
$$

where 


$$
\begin{gathered}
\mathrm{f}=(1-\varphi) \rho_{2}+\varphi \rho_{1}+\mu_{\mathrm{H}} \\
\mathrm{g}=\rho_{3}+\rho_{4}+\mu_{\mathrm{H}} \\
\mathrm{h}=\rho_{5}+\mu_{\mathrm{H}}, \mathrm{p}=\rho_{7}+\mathrm{d}_{1}+\mu_{\mathrm{H}} \\
\mathrm{q}=\rho_{6}+\mu_{\mathrm{H}}+\mathrm{d}_{2} \\
\mathrm{r}=\mu_{\mathrm{R}}+\rho_{\mathrm{R}}+\sigma_{R} \\
\mathrm{~s}=\mu_{\mathrm{R}}+\rho_{\mathrm{R}} \\
G=\frac{\partial F\left(E_{0}\right)}{\partial X}=\left[\begin{array}{cccccccc}
0 & 0 & 0 & \beta_{1} & \beta_{2} & \beta_{3} & \frac{\beta_{H} S_{H}^{0}}{N_{R}^{0}} & 0 \\
0 & 0 & 0 & 0 & 0 & 0 & 0 & 0 \\
0 & 0 & 0 & 0 & 0 & 0 & 0 & 0 \\
0 & 0 & 0 & 0 & 0 & 0 & 0 & 0 \\
0 & 0 & 0 & 0 & 0 & 0 & 0 & 0 \\
0 & 0 & 0 & 0 & 0 & 0 & 0 & 0 \\
0 & 0 & 0 & 0 & 0 & 0 & \beta_{R} & 0 \\
0 & 0 & 0 & 0 & 0 & 0 & 0 & 0
\end{array}\right]
\end{gathered}
$$

Here, $X=\left(E_{H}, E_{T H}, E_{N H}, I_{H}, I_{Q H}, D_{H}, E_{R}, I_{R}\right)$ is the infected compartments and

$$
U=\frac{\partial V\left(E_{0}\right)}{\partial X}=\left[\begin{array}{cccccccc}
f & 0 & 0 & 0 & 0 & 0 & 0 & 0 \\
-(1-\varphi) \rho_{2} & g & 0 & 0 & 0 & 0 & 0 & 0 \\
0 & -\varphi \rho_{1} & h & 0 & 0 & 0 & 0 & 0 \\
0 & 0 & -\rho_{5} & p & 0 & 0 & 0 & 0 \\
0 & -\rho_{4} & 0 & -\rho_{7} & q & 0 & 0 & 0 \\
0 & 0 & 0 & -d_{1} & -d_{2} & \gamma & 0 & 0 \\
0 & 0 & 0 & 0 & 0 & 0 & \mathrm{r} & 0 \\
0 & 0 & 0 & 0 & 0 & 0 & -\sigma_{R} & s
\end{array}\right]
$$

The basic reproduction number is computed using $R_{0}=\rho\left(\mathrm{GU}^{-1}\right)$ where $\rho($.$) is the spectral radius of the matrix, GU { }^{-1}$, i.e. the maximum eigenvalue ofGU ${ }^{-1}$.

This implies that

$$
R_{0}=\rho\left(\mathrm{GU}^{-1}\right)=\operatorname{Max}\left[\frac{\rho_{2}(1-\varphi)\left(\beta_{1} \rho_{1} \rho_{5} \varphi \gamma+A\right)}{\text { fghpq } \gamma}, \frac{\beta_{R} \rho_{r}}{\mathrm{~s}\left(\mathrm{~s}+\rho_{\mathrm{r}}\right)}\right]=\operatorname{Max}\left[R_{0 H}, R_{0 R}\right]
$$

where $A=\left(\beta_{2} \gamma+\beta_{3} d_{2}\right)\left(\rho_{4} p h+\varphi \rho_{1} \rho_{5} \rho_{7}\right)+\beta_{3} d_{1} \varphi \rho_{1} \rho_{5} q$.

$R_{0 H}$ and $R_{0 R}$ are the basic reproduction numbers for human and rodent population respectively.

\subsection{Stability Analysis}

Theorem 1. The disease - free equilibrium $E_{0}$ of the LASV model is locally asymptotically stable if $R_{0}<1$ and unstable if $R_{0}>1$.

Proof

We prove the Theorem 1 using linearization method.

The Jacobian matrix associated with the LASV model at the DFE, $E_{0}=\left(\frac{\Lambda_{H}}{\mu_{H}}, 0,0,0,0,0,0, \frac{\Lambda_{R}}{\mu_{R}+\rho_{R}}, 0,0\right)$ is given as

$$
J\left(\mathrm{E}_{0}\right)=\left[\begin{array}{cccccccccc}
-\mu_{H} & 0 & \rho_{3} & 0 & -\beta_{1} & -\beta_{2}+\rho_{6} & -\beta_{3} & 0 & 0 & -v \\
0 & -f & 0 & 0 & \beta_{1} & \beta_{2} & \beta_{3} & 0 & 0 & v \\
0 & (1-\varphi) \rho_{2} & -g & 0 & 0 & 0 & 0 & 0 & 0 & 0 \\
0 & \varphi \rho_{1} & 0 & -h & 0 & 0 & 0 & 0 & 0 & 0 \\
0 & 0 & 0 & \rho_{5} & -p & 0 & 0 & 0 & 0 & 0 \\
0 & 0 & \rho_{4} & 0 & \rho_{7} & -q & 0 & 0 & 0 & 0 \\
0 & 0 & 0 & 0 & d_{1} & d_{2} & -\gamma & 0 & 0 & 0 \\
0 & 0 & 0 & 0 & 0 & 0 & 0 & -s & 0 & -\beta_{R} \\
0 & 0 & 0 & 0 & 0 & 0 & 0 & 0 & -r & \beta_{R} \\
0 & 0 & 0 & 0 & 0 & 0 & 0 & 0 & \sigma_{R} & -s
\end{array}\right]
$$

The Eigenvalues of the Jacobian matrix, $J\left(\mathrm{E}_{0}\right)$ are

$$
-\mu_{h},-s,-s+\frac{1}{2} \rho_{r}+\frac{1}{2} \sqrt{4 \beta_{r} \rho_{r}+\rho_{r}^{2}},-s-\frac{1}{2} \rho_{r}-\frac{1}{2} \sqrt{4 \beta_{r} \rho_{r}+\rho_{r}^{2}}
$$


and the roots of

$$
\lambda^{6}+D \lambda^{5}+E \lambda^{4}+F \lambda^{3}+G \lambda^{2}+H \lambda+I=0
$$

where

$$
\begin{gathered}
D=p+\tau+f+g+h+q \\
E=f(q+g+h+\tau+\rho)+g(\tau+h+P+q)+\tau(h+p+q)+h(P+q)+p q \\
F=(1+\varphi) \beta_{2} \rho_{2} \rho_{4}+f g(\tau+h+\rho+q)+(f \tau+g \tau)(h+p+q)+(g h+\tau h+f h)(p+q)+ \\
p q(f+g+h+\tau) \\
G=\varphi(1-\varphi) \beta_{1} \rho_{1} \rho_{2} \rho_{5}+(1-\varphi) \beta_{2} \rho_{2} \rho_{4}(\tau+h+p)+(1-\varphi) \beta_{3} d_{2} \rho_{2} \rho_{4}+(f \tau h+g \tau h+f g h)(p+q) \\
+(f p q+g p q)(\tau+h)+f g(p q+\tau h) \\
H=\varphi(1-\varphi) \varphi \beta_{1} \rho_{1} \rho_{2} \rho_{5}(\tau+q)+(1-\varphi) \beta_{2} \rho_{1} \rho_{2} \rho_{5} \rho_{7}+(1-\varphi) \beta_{3} d_{1} \rho_{1} \rho_{2} \rho_{5}+(1-\varphi) \beta_{2} \rho_{2} \rho_{4} \\
{[\tau h+\tau p+h p]+(1-\varphi) \beta_{3} \rho_{2} \rho_{4} d_{2}(h+p)+f g \tau h(p+q)+f g h q(\tau+h)+\tau h p q(f+q)} \\
I=f g h p q \tau\left[R_{0 H}-1\right] .
\end{gathered}
$$

Using Routh - Hurwitz criteria, $E_{0}$ is locally asymptotically stable when $R_{0 H}<1$. This proves the theorem.

\subsection{Existence of Endemic Equilibrium}

Let denote the endemic equilibrium state by

$$
E_{I}=\left(S_{H}^{*}, E_{H}^{*} E_{T H}^{*}, E_{N T}^{*}, I_{H}^{*}, I_{Q H}^{*}, D_{H}^{*}, S_{R}^{*}, E_{R}^{*}, I_{R}^{*}\right)
$$

At the equilibrium,

$$
\frac{\mathrm{dS}_{\mathrm{H}}}{\mathrm{dt}}=\frac{\mathrm{dE}_{\mathrm{H}}}{\mathrm{dt}}=\frac{\mathrm{dE}_{\mathrm{TH}}}{\mathrm{dt}}=\frac{\mathrm{dE}_{\mathrm{NH}}}{\mathrm{dt}}=\frac{\mathrm{dI}_{\mathrm{H}}}{\mathrm{dt}}=\frac{\mathrm{dI}_{\mathrm{QH}}}{\mathrm{dt}}=\frac{\mathrm{dD}_{\mathrm{H}}}{\mathrm{dt}}=\frac{\mathrm{dS}_{\mathrm{R}}}{\mathrm{dt}}=\frac{\mathrm{dE}_{\mathrm{R}}}{\mathrm{dt}}=\frac{\mathrm{dI}_{\mathrm{R}}}{\mathrm{dt}}=0 .
$$

This gives

$$
\left.\begin{array}{c}
\Lambda_{\mathrm{H}}-\lambda_{\mathrm{H}} \mathrm{S}_{\mathrm{H}}-\mu_{\mathrm{H}} \mathrm{S}_{\mathrm{H}}+\rho_{3} \mathrm{E}_{\mathrm{TH}}+\rho_{6} \mathrm{I}_{\mathrm{QH}}=0 \\
\lambda_{\mathrm{H}} \mathrm{S}_{\mathrm{H}}-\mathrm{fE}_{\mathrm{H}}=0 \\
(1-\varphi) \rho_{2} \mathrm{E}_{\mathrm{H}}-\mathrm{gE}_{\mathrm{TH}}=0 \\
\varphi \rho_{1} \mathrm{E}_{\mathrm{H}}-\mathrm{hE}_{\mathrm{NH}}=0 \\
\rho_{5} \mathrm{E}_{\mathrm{NH}}-\mathrm{pI} \mathrm{I}_{\mathrm{H}}=0 \\
\rho_{7} \mathrm{I}_{\mathrm{H}}+\rho_{4} \mathrm{E}_{\mathrm{TH}}-\mathrm{qI} \mathrm{I}_{\mathrm{QH}}=0 \\
\mathrm{I}_{\mathrm{QH}}+\mathrm{d}_{1} \mathrm{I}_{\mathrm{H}}-\gamma \mathrm{D}_{\mathrm{H}}=0 \\
\Lambda_{\mathrm{R}}-\lambda_{\mathrm{R}} \mathrm{S}_{\mathrm{R}}-\mathrm{s} \mathrm{S}_{\mathrm{R}}=0 \\
\lambda_{\mathrm{R}} \mathrm{S}_{\mathrm{R}}-\left(\mathrm{s}+\sigma_{R}\right) \mathrm{E}_{\mathrm{R}}=0 \\
\sigma_{R} \mathrm{E}_{\mathrm{R}}-\mathrm{SI}_{\mathrm{R}}=0
\end{array}\right\}
$$

Where $f, g, h, p, q$, rands are same as defined in (9)

In solving (12) we let

$$
\lambda_{\mathrm{R}}=\frac{\mathrm{I}_{\mathrm{R}}}{\mathrm{N}_{\mathrm{R}}}=\frac{\mathrm{I}_{\mathrm{R}}}{\mathrm{S}_{\mathrm{R}}+\mathrm{E}_{\mathrm{R}}+\mathrm{I}_{\mathrm{R}}}
$$

So that

$$
\mathrm{E}_{\mathrm{R}}^{*}=\frac{\mathrm{sI}}{\sigma_{R}}, \quad S_{R}^{*}=\frac{\left(\sigma_{R}+s\right) s I_{R}}{\beta_{\mathrm{R}} \sigma_{R} \lambda_{\mathrm{R}}}, \quad \mathrm{I}_{\mathrm{R}}^{*}=\frac{\Lambda_{\mathrm{R}} \sigma_{R} \beta_{\mathrm{R}} \lambda_{\mathrm{R}}}{s\left(s \beta_{\mathrm{R}} \lambda_{\mathrm{R}}+\beta_{\mathrm{R}} \sigma_{R} \lambda_{\mathrm{R}}+\mathrm{s}^{2}+\mathrm{s} \sigma_{R}\right.}
$$

By substituting (14) in (13), we get

$$
\lambda_{\mathrm{R}}=\frac{\beta_{\mathrm{R}} \sigma_{R}-s\left(s+\sigma_{R}\right)}{\beta_{\mathrm{R}}\left(\sigma_{R}+s\right)}=0
$$

Which corresponds to the DFE. 
Recall that $R_{0 R}=\frac{\beta_{\mathrm{R}} \sigma_{R}}{s\left(s+\sigma_{R}\right)}$ in (10)

$$
\lambda_{\mathrm{R}}=\frac{s}{\beta_{\mathrm{R}}}\left(R_{0 R}-1\right)
$$

Substituting (16) into (14), we have

$$
\mathrm{I}_{\mathrm{R}}^{*}=\frac{\Lambda_{\mathrm{R}} \sigma_{R}}{s\left(s+\sigma_{R}\right)}\left(1-\frac{1}{R_{O R}}\right), \quad E_{R}^{*}=\frac{\Lambda_{\mathrm{R}}}{\left(s+\sigma_{R}\right)}\left(1-\frac{1}{R_{O R}}\right), \quad S_{R}^{*}=\frac{\Lambda_{\mathrm{R}}}{s R_{O R}}
$$

which exist if $R_{0 R}>1$.

By letting

$$
\lambda_{\mathrm{H}}^{*}=\frac{\beta_{\mathrm{H}} \mathrm{I}_{\mathrm{R}}^{*}}{\mathrm{~N}_{\mathrm{R}}^{*}}+\frac{\beta_{1} \mathrm{I}_{\mathrm{H}}^{*}+\beta_{2} \mathrm{I}_{\mathrm{QH}}^{*}+\beta_{3} \mathrm{D}_{\mathrm{H}}^{*}}{\mathrm{~N}_{\mathrm{H}}^{*}}
$$

in solving the first seven equations of (12) in terms of $\lambda_{\mathrm{H}}^{*}$, we get

$$
\begin{aligned}
\mathrm{S}_{\mathrm{H}}^{*}=\frac{\Lambda_{\mathrm{H}} \mathrm{fghpq}}{\mathrm{M}}, \mathrm{E}_{\mathrm{H}}^{*}=\frac{\lambda_{\mathrm{H}}^{*} \Lambda_{\mathrm{R}} \mathrm{ghpq}}{\mathrm{M}}, \mathrm{E}_{\mathrm{TH}}^{*} & =\frac{a \sigma_{R} \Lambda_{\mathrm{R}} \mathrm{hpq} \lambda_{\mathrm{H}}^{*}}{\mathrm{M}}, \mathrm{E}_{\mathrm{NH}}^{*}=\frac{\varphi \rho_{1} v \rho_{2} \Lambda_{\mathrm{H}} \mathrm{pq} \lambda_{\mathrm{H}}}{\mathrm{M}}, \mathrm{I}_{\mathrm{H}}^{*}=\frac{\rho_{5} \varphi \rho_{1} v \rho_{2} \Lambda_{\mathrm{H}} \mathrm{q} \lambda_{\mathrm{H}}}{\mathrm{M}}, \mathrm{I}_{\mathrm{QH}}^{*} \\
& =\frac{v \rho_{2} \Lambda_{\mathrm{H}} \lambda_{\mathrm{H}}\left(\varphi \rho_{1} \rho_{5} \rho_{7}+h p \rho_{7}\right)}{\mathrm{M}}
\end{aligned}
$$

and

$$
\mathrm{D}_{\mathrm{H}}^{*}=\frac{v \Lambda_{\mathrm{H}} \rho_{2} \lambda_{\mathrm{H}}\left(\varphi \mathrm{qd}_{1} \rho_{1} \rho_{5}+\varphi \mathrm{d}_{2} \rho_{1} \rho_{5} \rho_{7}+\operatorname{hpd}_{2} \rho_{4}\right)}{M \tau}
$$

Where $K=f g h p q \mu_{H}+f g h p q \lambda_{\mathrm{H}}^{*}-\lambda_{\mathrm{H}}^{*} \rho_{2} \mathrm{v}\left(\rho_{3} \mathrm{hpq}+\varphi \rho_{1} \rho_{5} \rho_{7}+\mathrm{hp} \rho_{4}\right)$ and $v=(1-\varphi)$.

If we substitute $\mathrm{S}_{\mathrm{H}}^{*}, \mathrm{E}_{\mathrm{H}}^{*}, \mathrm{E}_{\mathrm{TH}}^{*}, \mathrm{E}_{\mathrm{NH}}^{*}, \mathrm{I}_{\mathrm{H}}^{*}, \mathrm{I}_{\mathrm{QH}}^{*}$ and $\mathrm{D}_{\mathrm{H}}^{*}$ into (14) and set

$$
\rho\left(\lambda_{\mathrm{H}}^{*}\right)=\lambda_{\mathrm{H}}^{*}-\frac{\beta_{\mathrm{H}} \mathrm{I}_{\mathrm{R}}^{*}}{\mathrm{~N}_{\mathrm{R}}^{*}}-\frac{\beta_{1} \mathrm{I}_{\mathrm{H}}^{*}+\beta_{2} \mathrm{I}_{\mathrm{QH}}^{*}+\beta_{3} \mathrm{D}_{\mathrm{H}}^{*}}{\mathrm{~N}_{\mathrm{H}}^{*}}=0
$$

We obtained the following equation

$$
\lambda_{\mathrm{H}}^{*}\left(\mathrm{M} \lambda_{\mathrm{H}}^{* 2}+\mathrm{N} \lambda_{\mathrm{H}}^{*}+\mathrm{P}\right)=0
$$

where

$$
\begin{gathered}
M=\beta_{\mathrm{R}}\left(\operatorname{vhpd}_{2} \rho_{2} \rho_{4}+q v \rho_{2} \operatorname{hp} \tau+\tau \operatorname{vhp} \rho_{2} \rho_{4}+\varphi \rho_{1} \mathrm{v} \rho_{2} \mathrm{pq} \tau+\varphi \rho_{1} \mathrm{v} \rho_{2} \mathrm{pq} \tau+\rho_{5} \varphi \rho_{1} \mathrm{v} \rho_{2} \mathrm{q} \tau+\tau \mathrm{v} \varphi \rho_{1} \rho_{2} \rho_{5} \rho_{7}\right. \\
+\operatorname{veqd} \rho_{1} \rho_{25 \mathrm{rpd}} \\
\mathrm{N}=\beta_{\mathrm{H}} \operatorname{sv} \varphi \rho_{2}\left(\tau \rho_{1} \rho_{25 \mathrm{rpd}}\right) \\
\beta_{\mathrm{R}} \operatorname{shp}\left(\tau \mathrm{v} \rho_{2} \rho_{4}+\operatorname{v} \rho_{2} \mathrm{q} \tau+\mathrm{vd}_{2} \rho_{2} \rho_{4}+\mathrm{qg} \tau\right)\left(1-\mathrm{R}_{0 \mathrm{R}}\right) \\
P=\beta_{\mathrm{H}} \operatorname{sfghpq} \tau\left(1-\mathrm{R}_{0 \mathrm{R}}\right)
\end{gathered}
$$

Hence, (17) $\lambda_{\mathrm{H}}^{*}=0$ corresponds to the DFE already obtained

Now, the solution of the quadratic equation

$$
\mathrm{M} \lambda_{\mathrm{H}}^{* 2}+\mathrm{N} \lambda_{\mathrm{H}}^{*}+\mathrm{P}=0
$$

depends on the signs of the coefficients, $\mathrm{M}, \mathrm{N}$, and $P$.

Using Descarte's rule of signs to determine the sign of $\lambda_{\mathrm{H}}^{*}$ in (18), a unique positive endemic equilibrium, $\lambda_{\mathrm{H}}^{*}$ exists if MandP are both negative. This happens when $\mathrm{R}_{0 \mathrm{R}}>$ 1and $\mathrm{R}_{0 \mathrm{H}}>1$ which implies $\mathrm{R}_{0}>1$.

\subsection{Local Stability of the Endemic Equilibrium}

We use the approach of centre manifold theory described by Castillo - Chavez and Song [4] to investigate the stability of endemic equilibrium near $R_{0}=1$. It is used to examine the existence of forward bifurcation at $R_{0}=1$. When the bifurcation is forward, it implies that disease free equilibrium is locally asymptotically stable for $R_{0}<1$ and there is no disease in the population and also endemic equilibrium is locally asymptotically stable for $R_{0}>1$ near one. This means that disease cannot invade the population when $R_{0}<1$.

Let consider $\beta_{1}$ and $\beta_{r}$ as the bifurcation parameters at $R_{0}=1$, so that $R_{0 R}=1$ and $R_{0 H}=1$ if and only if 


$$
\beta_{r}=\beta_{r}^{*}=\frac{s\left(s+\rho_{r}\right)}{\rho_{r}} \quad \beta_{1}=\beta_{1}^{*}=\frac{f g h p q \tau-\rho_{2} H}{\rho_{r} \rho_{5} q \varphi \tau}
$$

and

Then, we make the following change of variables

$$
\begin{gathered}
S_{H}=x_{1}, E_{H}=x_{2}, E_{T H}=x_{3}, E_{N H}=x_{4}, I_{H}=x_{5}, I_{Q H}=x_{6}, D_{H}=x_{7}, S_{R}=x_{8}, \\
E_{R}=x_{9}, I_{R}=x_{10}
\end{gathered}
$$

Then the LASV model of equations (5) - (14) can be written in the form

$$
\frac{d x_{i}}{d t}=F\left(x_{i}\right), i=1,2,3, \ldots, 10
$$

where

$$
F=\left(f_{1}, f_{2}, f_{3}, f_{4}, f_{5}, f_{6}, f_{7}, f_{8}, f_{9}, f_{10}\right)^{T}
$$

and

$$
X=\left(x_{1}, x_{2}, x_{3}, x_{4}, x_{5}, x_{6}, x_{7}, x_{8}, x_{9}, x_{10}\right)^{T} .
$$

This gives

$$
\left.\begin{array}{c}
\frac{d x_{1}}{d t}=\Lambda_{H}-\lambda_{H} x_{1}-\mu_{H} x_{1}+\rho_{3} x_{3}+\rho_{6} x_{6}=f_{1} \\
\frac{d x_{2}}{d t}=\lambda_{H} S_{H}-f_{x_{2}}=f_{2} \\
\frac{d x_{3}}{d t}=(1-\varphi) \rho_{2} x_{2}-g x_{3}=f_{3} \\
\frac{d x_{4}}{d t}=\varphi \rho_{1} x_{3}-h x_{4}=f_{4} \\
\frac{d x_{5}}{d t}=\rho_{5} x_{4}-\mathrm{px}_{5}=f_{5} \\
\frac{d x_{6}}{d t}=\rho_{7} x_{5}+\rho_{4} x_{3}-\mathrm{qx}_{6}=f_{6} \\
\frac{d x_{7}}{d t}=d_{2} x_{6}+d_{1} x_{5}-\gamma x_{7}=f_{7} \\
\frac{d x_{8}}{d t}=\Lambda_{R}-\lambda_{R} x_{8}-S x_{8}=f_{8} \\
\frac{d x_{9}}{d t}=\lambda_{R} x_{8}-\left(\rho_{r}+S\right) x_{9}=f_{9} \\
\frac{d I_{R}}{d t}=\rho_{r} x_{9}-S x_{10}=f_{10}
\end{array}\right\}
$$

With $\lambda_{\mathrm{H}}=\frac{\beta_{\mathrm{H}} \mathrm{x}_{10}}{\mathrm{~N}_{\mathrm{R}}}+\frac{\beta_{1} \mathrm{x}_{5}+\beta_{2} \mathrm{x}_{6}+\beta_{3} \mathrm{x}_{7}}{\mathrm{~N}_{\mathrm{H}}}, \lambda_{\mathrm{R}}=\frac{\beta_{\mathrm{R}} \mathrm{x}_{10}}{\mathrm{~N}_{\mathrm{R}}}$ and $\mathrm{N}_{\mathrm{R}}=\mathrm{x}_{8}+\mathrm{x}_{9}+\mathrm{x}_{10}, \mathrm{~N}_{\mathrm{H}}=\mathrm{x}_{1}+\mathrm{x}_{2}+\mathrm{x}_{3}+\mathrm{x}_{4}+\mathrm{x}_{5}+\mathrm{x}_{7}$.

Using the Jacobian Matrix $J\left(E_{0}\right)$ in (11) at $R_{0}=1$, the roots of equation (32) will have a zero eigenvalue, Since

$$
F=\operatorname{fghpq} \tau\left(R_{0 H}-1\right)=0 \text { when } R_{0 H}=1
$$

So that

$$
\begin{gathered}
\lambda\left(\lambda^{5}+A \lambda^{4}+B \lambda^{3}+C \lambda^{2}+D \lambda+E\right)=0 \\
\lambda=0 \operatorname{or}\left(\lambda^{5}+A \lambda^{4}+B \lambda^{3}+C \lambda^{2}+D \lambda+E\right)=0 .
\end{gathered}
$$

We first calculate the right eigenvector of $J\left(E_{0}\right)$ denoted by

$$
w=\left(w_{1}, w_{2}, w_{3}, w_{4}, w_{5}, w_{6}, w_{7}, w_{8}, w_{9}, w_{10}\right)^{T}
$$

By multiplying it with the Jacobian matrix and equating to zero.

We have

$$
\begin{gathered}
w_{3}=\frac{(1-\varphi) \rho_{2}}{g} w_{2}, w_{4}=\frac{\varphi \rho_{1}}{h} w_{3}, \quad w_{5}=\frac{\rho_{5}}{p} w_{4}, \quad w_{6}=\frac{\rho_{4} w_{4}+\rho_{7} w_{5}}{q}, \quad w_{7}=\frac{d_{1} w_{5}+d_{2} w_{6}}{e}, \\
w_{8}=\frac{-f w_{2}+\beta_{1} w_{5}+\beta_{2} w_{6}+\beta_{3} w_{7}}{\gamma}=0
\end{gathered}
$$




$$
\begin{gathered}
\text { at } R_{0 H}=1, \quad w_{9}=0, \quad w_{10}=0, \quad w_{2}=w_{2}>0 \\
w_{1}=\frac{\rho_{3} w_{3}-\tau \beta_{1} w_{5}+\left(-\beta_{2}+\rho_{0}\right) w_{6}-\beta_{3} w_{7}}{\mu_{h}} .
\end{gathered}
$$

The left eigenvector of the Jacobian $J\left(E_{0}\right)$ associated with the zero eigenvector is given by

$$
u=\left(u_{1}, u_{2}, u_{3}, \ldots, u_{10}\right)^{T}
$$

This is computed by transposing $J\left(E_{0}\right)$ first and multiply by $u$.

We get

$$
\begin{gathered}
u_{1}=0, \quad u_{3}=\frac{f}{(1-\varphi) \rho_{2}} u_{2}, \quad u_{4}=\frac{g u_{3}-\rho_{4} u_{6}}{\varphi \rho_{1}}, \quad u_{5}=\frac{h u_{4}}{\rho_{5}}, \quad u_{6}=\frac{\beta_{2} u_{2}+d_{2} u_{7}}{q}, \quad u_{7}=\frac{\beta_{3}}{\tau} u_{2}, \quad u_{8}=\frac{v u_{2}}{s}, \\
u_{9}=\frac{v}{s(1-s)} u_{2}, \quad u_{10}=\frac{\beta_{r}^{*}}{s} u_{9}, \quad u_{2}=u_{2}>0 .
\end{gathered}
$$

$w_{2}$ and $u_{2}$ are computed to ensure that the eigenvector satisfy the property.

The coefficients $a$ and $b$ as defined in Theorem 4.1 of [4] are given as

$$
\begin{gathered}
a=\sum_{k, j, i=1}^{n} u_{k} w_{i} w_{j} \frac{\partial^{2} f_{k}\left(E_{0}\right)}{\partial x_{i} \partial x_{j}} \\
b=\sum_{k, j, i=1}^{n} u_{k} w_{i} \frac{\partial^{2} f_{k}\left(E_{0}\right)}{\partial x_{i} \partial \beta_{i}}
\end{gathered}
$$

We can only consider when $k=s$ since it will give us nonzero partial derivatives at the DFE, $E_{0}$. So, function, $f_{2}$, is considered and is defined in (48). The associated nonzero partial derivatives at the DFE and $\beta_{r}^{*}=\beta_{1}$ and $\beta_{1}^{*}=\beta_{1}$ are given by

$$
\begin{gathered}
\frac{\partial^{2} f_{2}}{\partial x_{7} \partial x_{2}}=-\frac{\beta_{3}}{N_{H}}, \frac{\partial^{2} f_{2}}{\partial x_{7} \partial x_{3}}=-\frac{\beta_{3}}{N_{H}}, \frac{\partial^{2} f_{3}}{\partial x_{7} \partial x_{4}}=-\frac{\beta_{3}}{N_{H}}, \\
\frac{\partial^{2} f_{2}}{\partial x_{7} \partial x_{6}}=-\frac{\beta_{3}}{N_{H}}-\frac{\beta_{1}}{N_{H}}, \frac{\partial^{2} f_{2}}{\partial x_{7} \partial x_{5}}=-\frac{\beta_{3}}{N_{H}}-\frac{\beta_{1}}{N_{H}}, \frac{\partial^{2} f}{\partial x_{7}^{2}}=-2 \frac{\beta_{3}}{N_{H}}, \\
\frac{\partial^{2} f}{\partial x_{6}^{2}}=-2 \frac{\beta_{2}}{N_{H}}, \frac{\partial^{2} f}{\partial x_{5} \partial x_{3}}=\frac{\partial^{2} f}{\partial x_{5} \partial x_{2}}=\frac{\partial^{2} f}{\partial x_{5} \partial x_{4}}=-\frac{\beta_{1}}{N_{H}}, \frac{\partial^{2} f}{\partial x_{5}^{2}}=-2 \frac{\beta_{1}}{N_{H}}, \frac{\partial^{2} f}{\partial x_{5} \partial \beta_{1}}=1 .
\end{gathered}
$$

This implies that

$$
\begin{gathered}
a=-\frac{u_{2}}{N_{H}}\left[w_{5} w_{2} \beta_{1}+w_{5} w_{3} \beta_{1}+2 w_{5}^{2} \beta_{1}+w_{5} w_{6} \beta_{1}+w_{5} w_{6} \beta_{2}+w_{5} w_{4} \beta_{1}+w_{5} w_{7} \beta_{1}+w_{5} w_{7} \beta_{3}+w_{6} w_{2} \beta_{2}+w_{6} w_{3} \beta_{2}+\right. \\
\left.w_{6} w_{4} \beta_{2}+w_{6} w_{7} \beta_{3}+w_{6} w_{7} \beta_{2}+2 w_{6}^{2} \beta_{2}+w_{7} w_{2} \beta_{3}+w_{7} w_{3} \beta_{3}+w_{7} w_{4} \beta_{3}+2 w_{7}^{2} \beta_{3}\right] .
\end{gathered}
$$

This gives $a<0$, since $w_{2}, w_{3}, w_{7}, w_{5}, w_{6}, w_{7}$ and $u_{2}>0$ and

$$
b=u_{2} w_{5} \frac{\partial^{2} f_{2}}{\partial w_{2} \partial \beta_{1}}=u_{2} w_{5}>0
$$

Thus, using theorem 4.1 of Castillo-Chavez and Song (2004), the endemic equilibrium $E_{1}$ is locally asymptotically stable for $\mathrm{R}_{\mathrm{O}}>1$, but close to unity.

\section{Numerical Simulation and Discussion}

\subsection{Numerical Simulations}

Numerical simulation for the model were carried out using the parameter values in Table 2. The model parameters were sourced from existing literatures where available, while others were logically estimated for the purpose of illustrations to fit the model analyses. The Lassa fever infection data for Ebonyi State, Nigeria used for this simulation were sourced from the weekly Situation report of the Nigeria Centre for Disease control (NCDC) on Lassa fever from January, 2018 to September, 2019 as presented in Table 3 and Table 4 with the time series graph of the data shown on figure2, figure 3 and figure 4 . The program codes were written and implemented on MATLAB encoded with ODE45 solver to simulate the model system using the parameters values. 
Table 2. Model Parameter Values.

\begin{tabular}{|c|c|c|c|}
\hline $\begin{array}{l}\text { Variables/P } \\
\text { arameters }\end{array}$ & Description & Values & References \\
\hline$\Lambda_{H}$ & Recruitment rate into susceptible human population either through birth or immigration & 2000 & [14] \\
\hline$\Lambda_{R}$ & Recruitment rate into susceptible Rat population either through birth or immigration & 500 & [14] \\
\hline$\mu_{H}$ & Natural death rate of humans & 0.02 & CIA, 2017 \\
\hline$\mu_{R}$ & Rodent Natural death rate in the rodent reservoir & 0.02 & [14] \\
\hline$\beta_{1}$ & $\begin{array}{l}\text { Effective contact rates between quarantined-infectious human and susceptible humans per contact in the } \\
\text { compartments } I_{Q H} \text {, }\end{array}$ & 0.2 & [14] \\
\hline$\beta_{2}$ & $\begin{array}{l}\text { Effective contact rates between not-quarantined infectious human and susceptible humans per contact in } \\
\text { the compartments } I_{H}\end{array}$ & 0.1 & Estimated \\
\hline$\beta_{3}$ & $\begin{array}{l}\text { Effective contact rates between Infectious human corpse and susceptible humans per contact in the } \\
\text { compartments } D_{H}\end{array}$ & 0.2 & [14] \\
\hline$\beta_{H}$ & Effective contact rate between infectious rodent or its contaminants with susceptible human per contact & 0.08 & [14] \\
\hline$\beta_{R}$ & Effective contact rate between infectious rodent and susceptible rodent per contact & 0.02 & Estimated \\
\hline$\rho_{R}$ & Death rate of rodent from predators hunting/ human induced control measures & 0.01 & [15] \\
\hline$\sigma_{R}$ & Rate at which exposed rodent progress to infectious class & & \\
\hline$\rho_{1}$ & Rate at which exposed humans escaped being quarantine & & \\
\hline$\rho_{2}$ & Quarantine rate of humans & 0.25 & Estimated \\
\hline$\rho_{3}$ & Recovery rate of quarantined humans & 0.05 & Estimated \\
\hline$\rho_{4}$ & Isolation rate of quarantined-infectious humans & 0.5 & [16] \\
\hline$\rho_{5}$ & Infectious rate of not-quarantined humans & 0.03 & [15] \\
\hline$\rho_{6}$ & Recovery rate of isolated humans & 0.6 & [16] \\
\hline$\rho_{7}$ & Isolation rate of not-quarantined infectious human & 0.2 & Estimated \\
\hline$d_{1}$ & Disease induced death rate of infectious not isolated humans & 0.2 & [14] \\
\hline$d_{2}$ & Disease induced death rate of isolated humans & 0.15 & Estimated \\
\hline$\varphi$ & Proportion of exposed human that are not quarantined & & \\
\hline$\gamma$ & Burial rate of death Infectious corpse & & \\
\hline
\end{tabular}

Table 3. Weekly Lassa Fever Confirm Infections recorded in Ebonyi State, Eastern Nigeria (The year 2018).

\begin{tabular}{|c|c|c|c|}
\hline Epidemiological weeks & infected & Epidemiological weeks & infected \\
\hline 1 & 0 & 27 & 0 \\
\hline 2 & 4 & 28 & 0 \\
\hline 3 & 4 & 29 & 0 \\
\hline 4 & 0 & 30 & 0 \\
\hline 5 & 0 & 31 & 0 \\
\hline 6 & 2 & 32 & 0 \\
\hline 7 & 7 & 33 & 0 \\
\hline 8 & 18 & 34 & 1 \\
\hline 9 & 9 & 35 & 0 \\
\hline 10 & 1 & 36 & 0 \\
\hline 11 & 0 & 37 & 0 \\
\hline 12 & 2 & 38 & 0 \\
\hline 13 & 0 & 39 & 0 \\
\hline 14 & 1 & 40 & 2 \\
\hline 15 & 1 & 41 & 2 \\
\hline 16 & 0 & 42 & 0 \\
\hline 17 & 0 & 43 & 1 \\
\hline 18 & 1 & 44 & 1 \\
\hline 19 & 1 & 45 & 0 \\
\hline 20 & 0 & 46 & 0 \\
\hline 21 & 0 & 47 & 0 \\
\hline 22 & 0 & 48 & 0 \\
\hline 23 & 0 & 49 & 0 \\
\hline 24 & 0 & 50 & 0 \\
\hline 25 & 0 & 51 & 0 \\
\hline 26 & 0 & 52 & 0 \\
\hline
\end{tabular}


Table 4. Weekly Lassa Fever Confirm Infections recorded in Ebonyi State, Eastern Nigeria (January, 2019 - September, 2019).

\begin{tabular}{llll}
\hline Epidemiological weeks & infected & Epidemiological weeks & infected \\
\hline 1 & 1 & 23 & 0 \\
2 & 5 & 24 & 0 \\
3 & 2 & 25 & 0 \\
4 & 5 & 26 & 0 \\
5 & 7 & 27 & 0 \\
6 & 4 & 28 & 3 \\
7 & 1 & 29 & 0 \\
8 & 0 & 30 & 0 \\
9 & 2 & 31 & 0 \\
10 & 9 & 32 & 0 \\
11 & 3 & 33 & 0 \\
12 & 1 & 34 & 0 \\
13 & 0 & 35 & 0 \\
14 & 1 & 36 & 1 \\
15 & 0 & 37 & \\
16 & 0 & 38 & \\
17 & 0 & 39 & \\
18 & 0 & 40 & \\
19 & 1 & 41 & \\
20 & 0 & 42 & \\
21 & 0 & 43 & \\
22 & 0 & 44 & \\
\hline
\end{tabular}

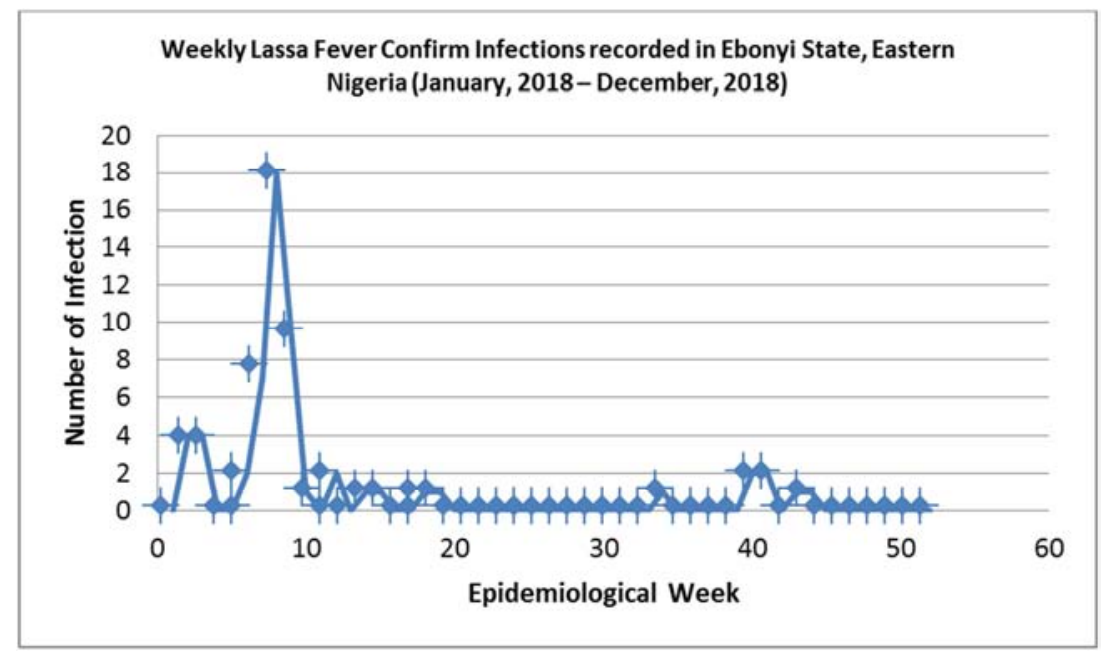

Figure 2. Graph of Weekly Confirm Infections of Lassa Fever in Ebonyi State, Eastern Nigeria (January, 2018-December, 2018).

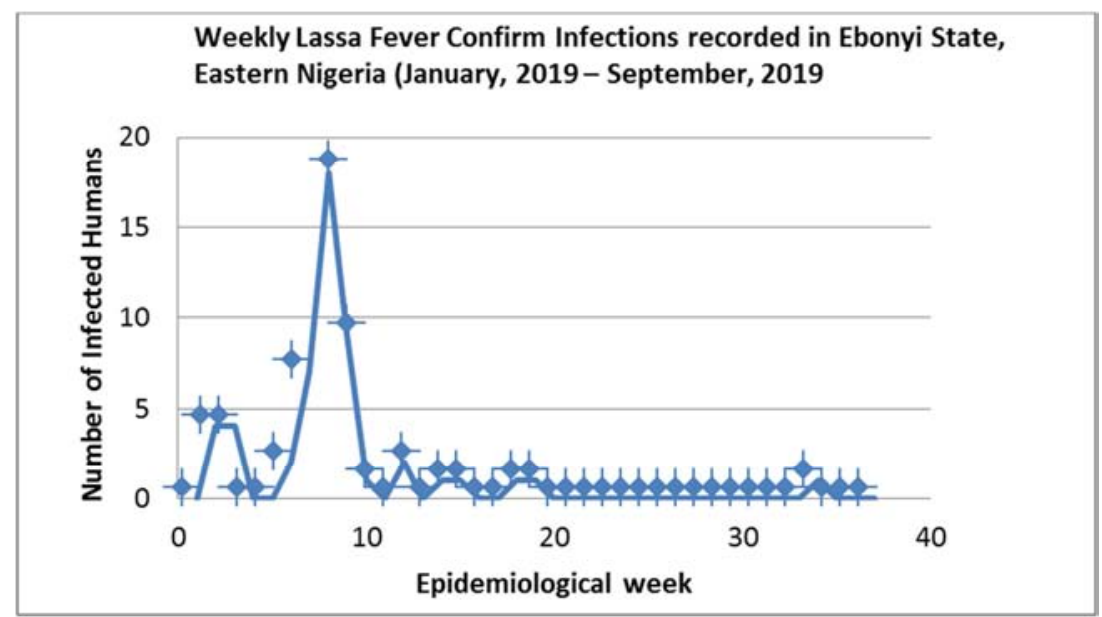

Figure 3. Graph of Weekly Confirm Infections of Lassa Fever in Ebonyi State, Eastern Nigeria (January, 2019-September, 2019). 


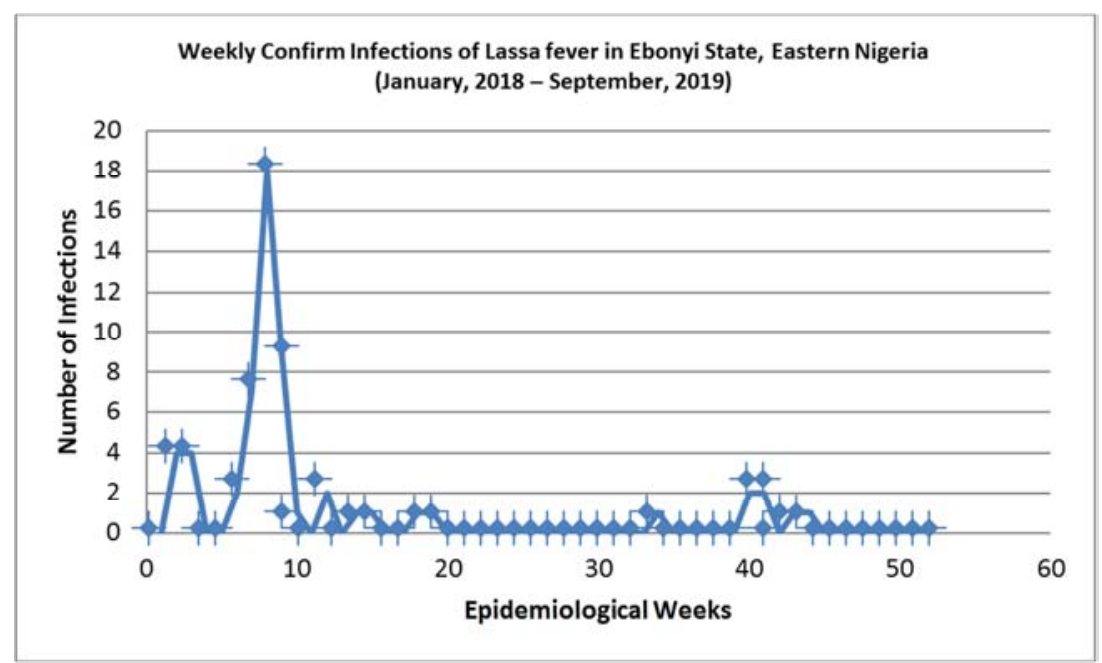

Figure4. Graph of Weekly Confirm Infections of Lassa Fever in Ebonyi State, Eastern Nigeria (January, 2018 - September, 2019).

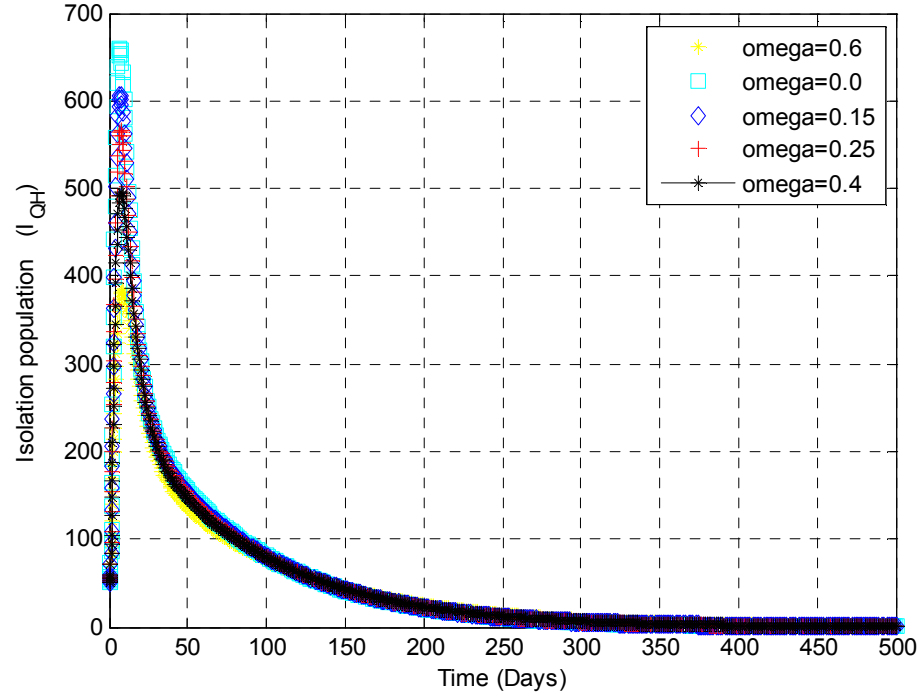

(a)

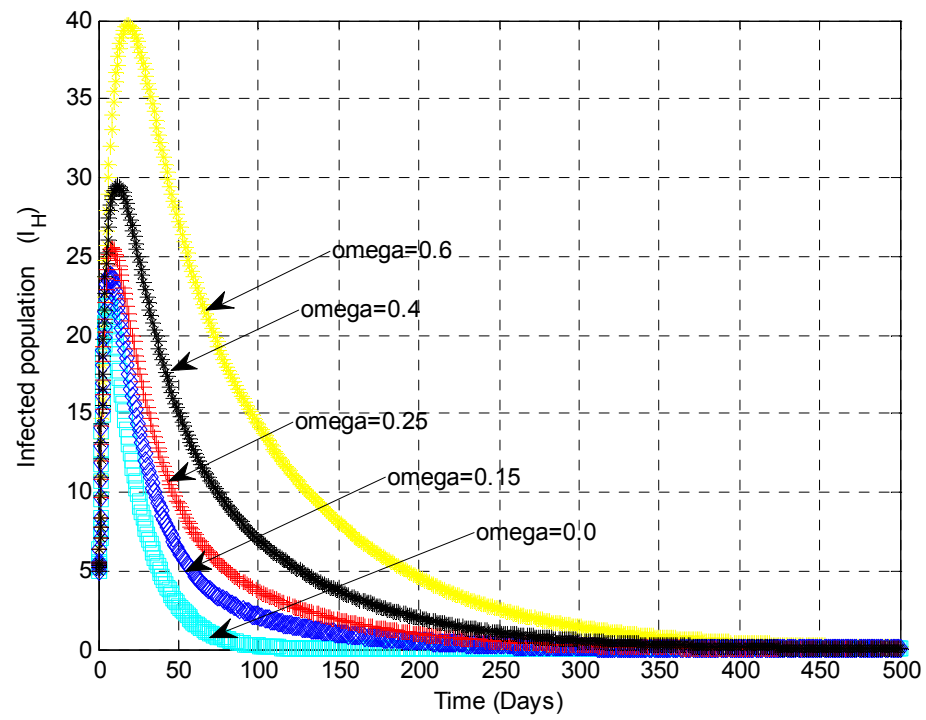

(b)

Figure 5. Simulations showing the effect of the proportion of humans not quarantine, $\varphi$, on the LASV transmission dynamics. 


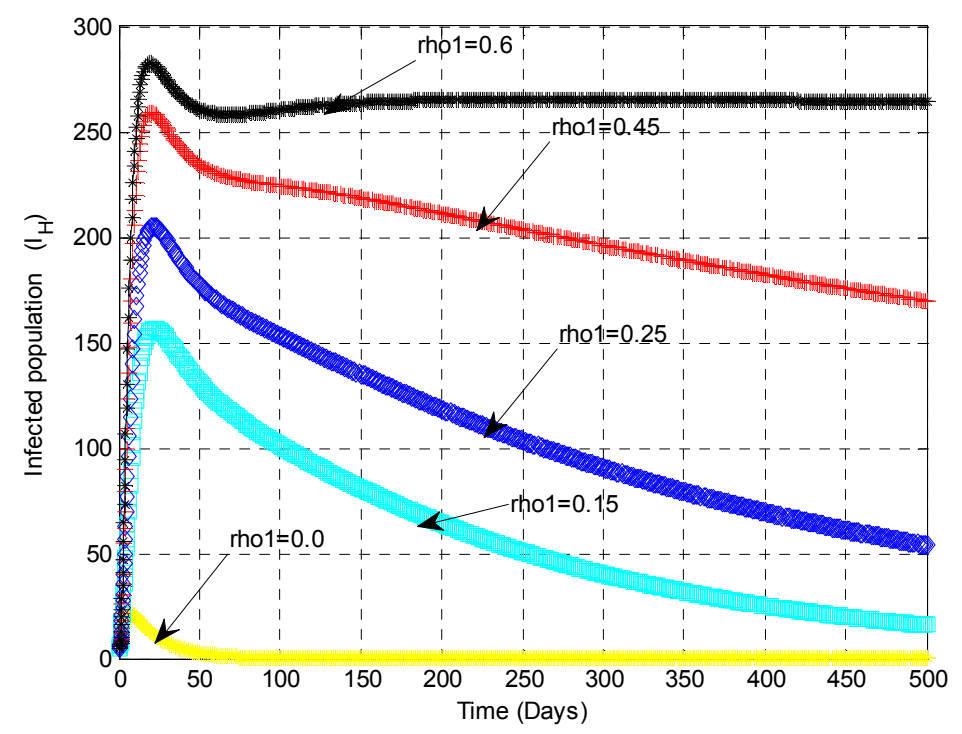

(a)

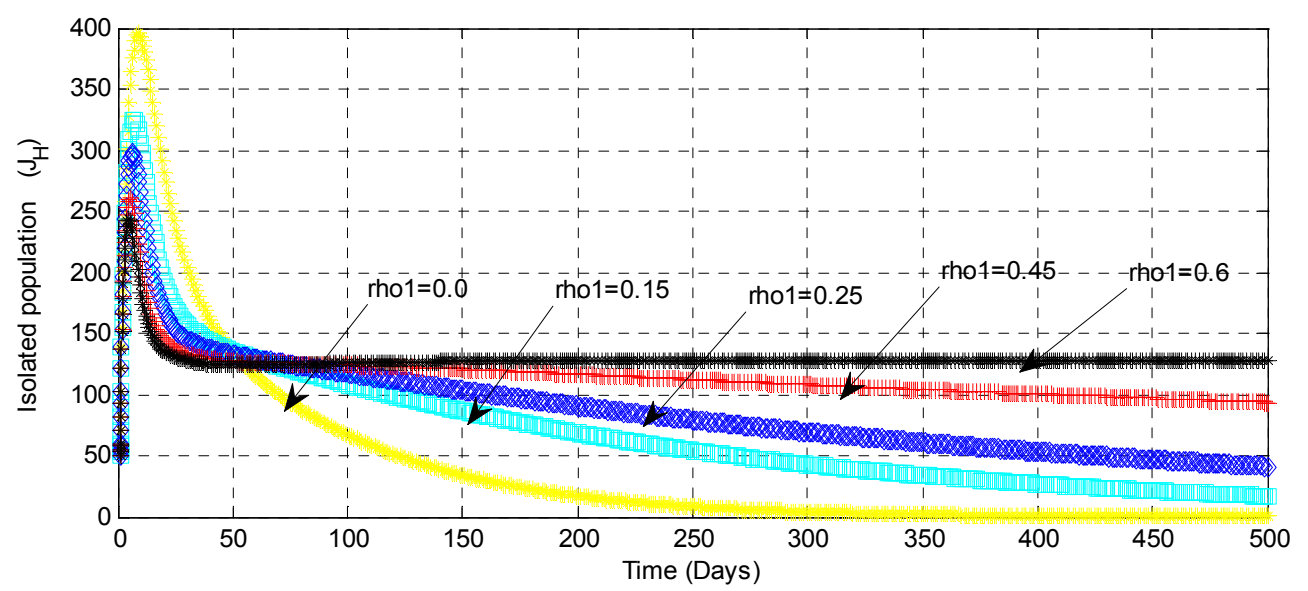

(b)

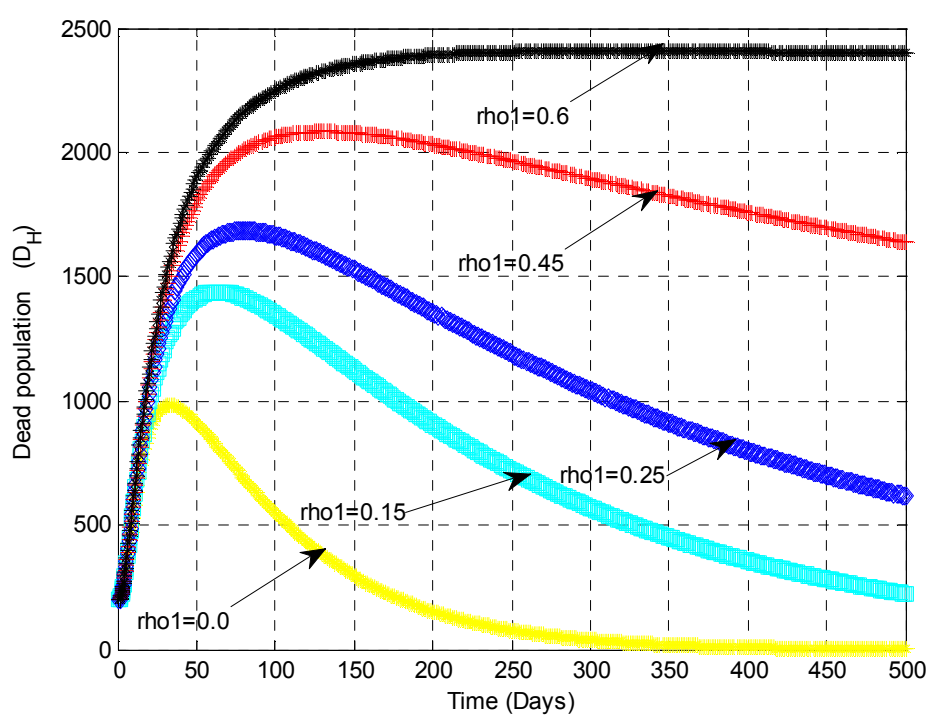

(c)

Figure 6. Simulations showing the effect of not-quarantining exposed humans, $\rho_{1}$, on the LASV transmission dynamics. 


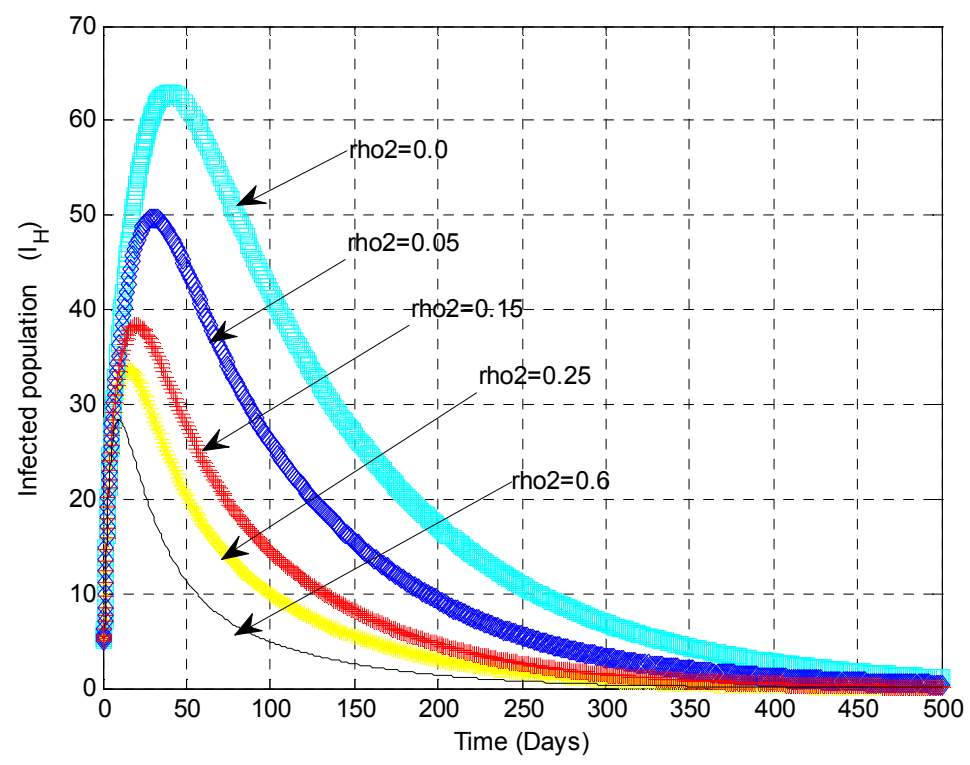

(a)

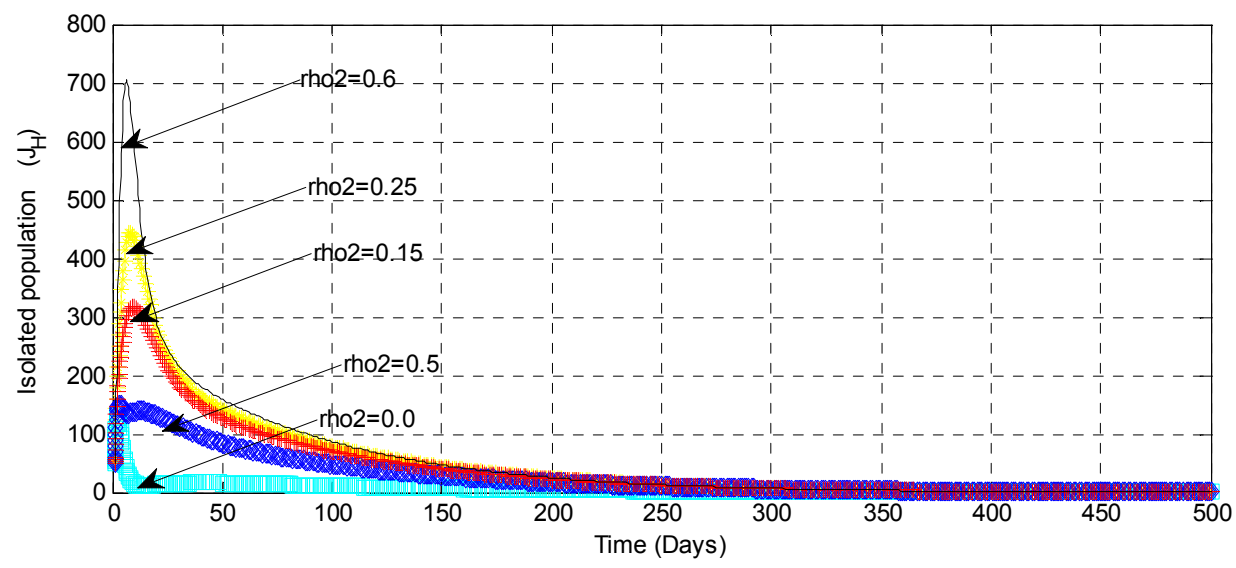

(b)

Figure 7. Simulations showing the effect quarantining the exposed humans, $\rho_{2}$, on the LASV transmission dynamics.

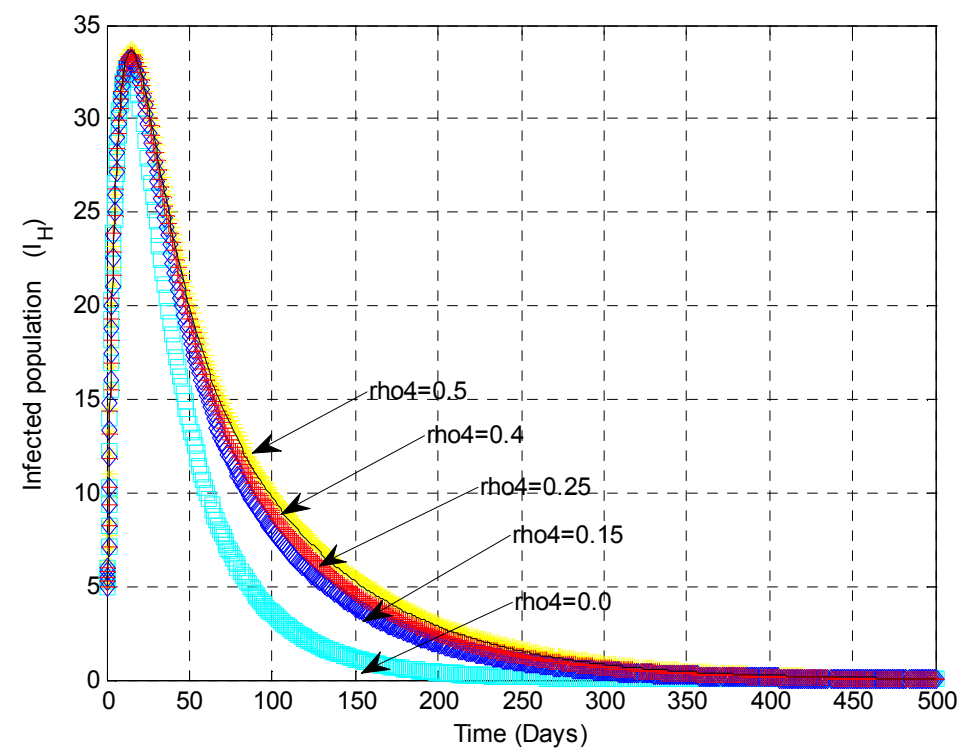

(a) 


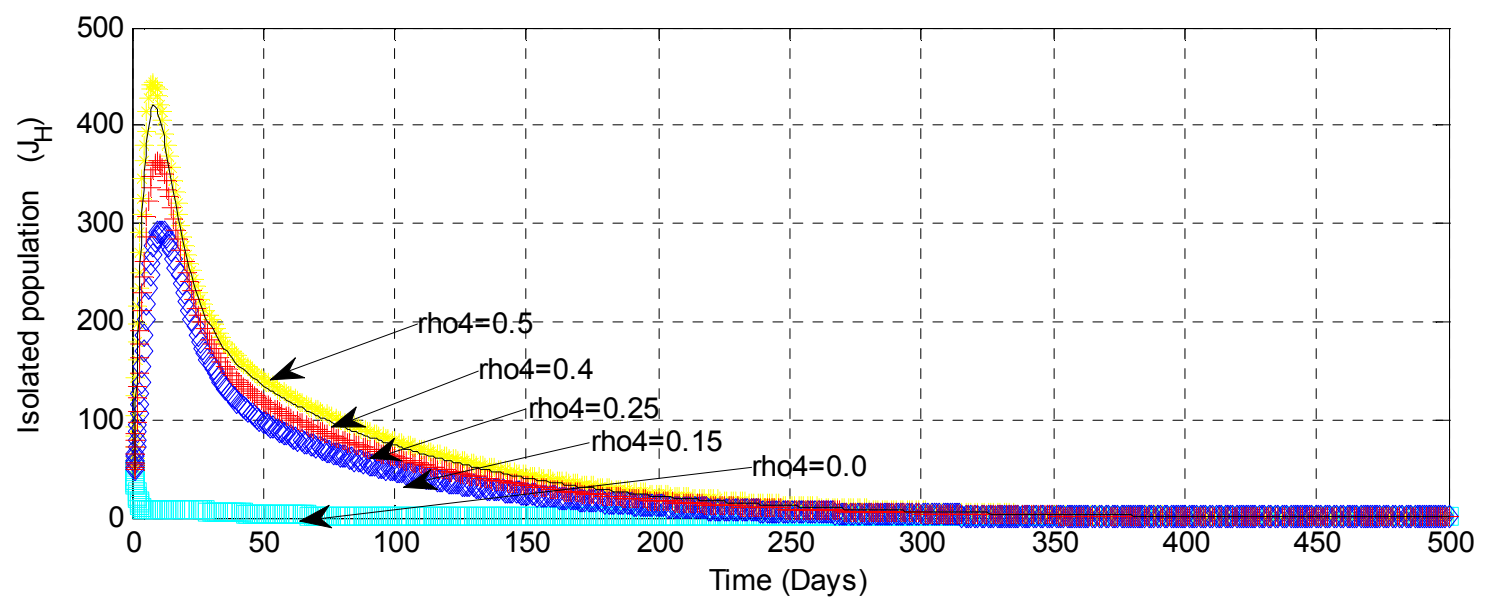

(b)

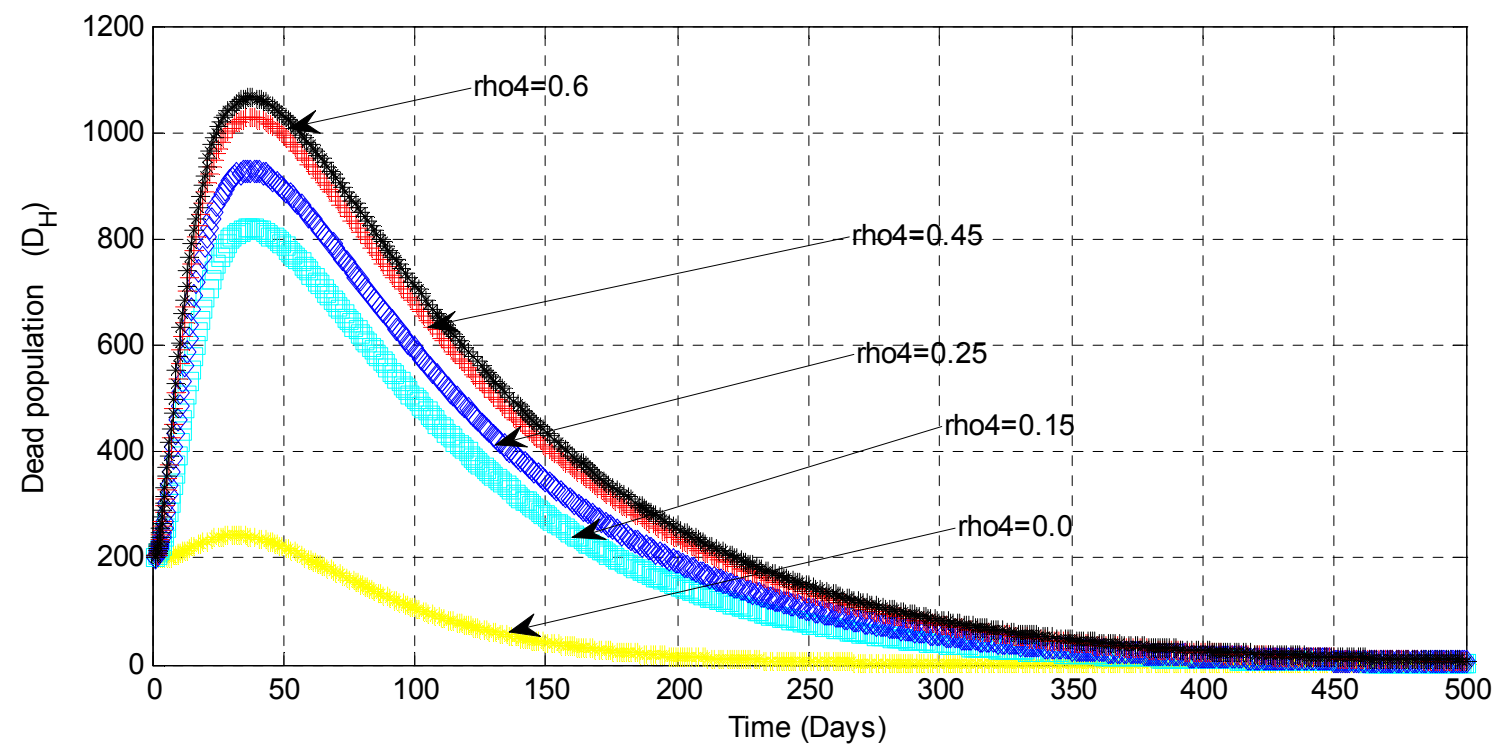

(c)

Figure 8. Simulations showing the effect of isolating the quarantined humans for treatment, $\rho_{4}$, on the LASV transmission dynamics.

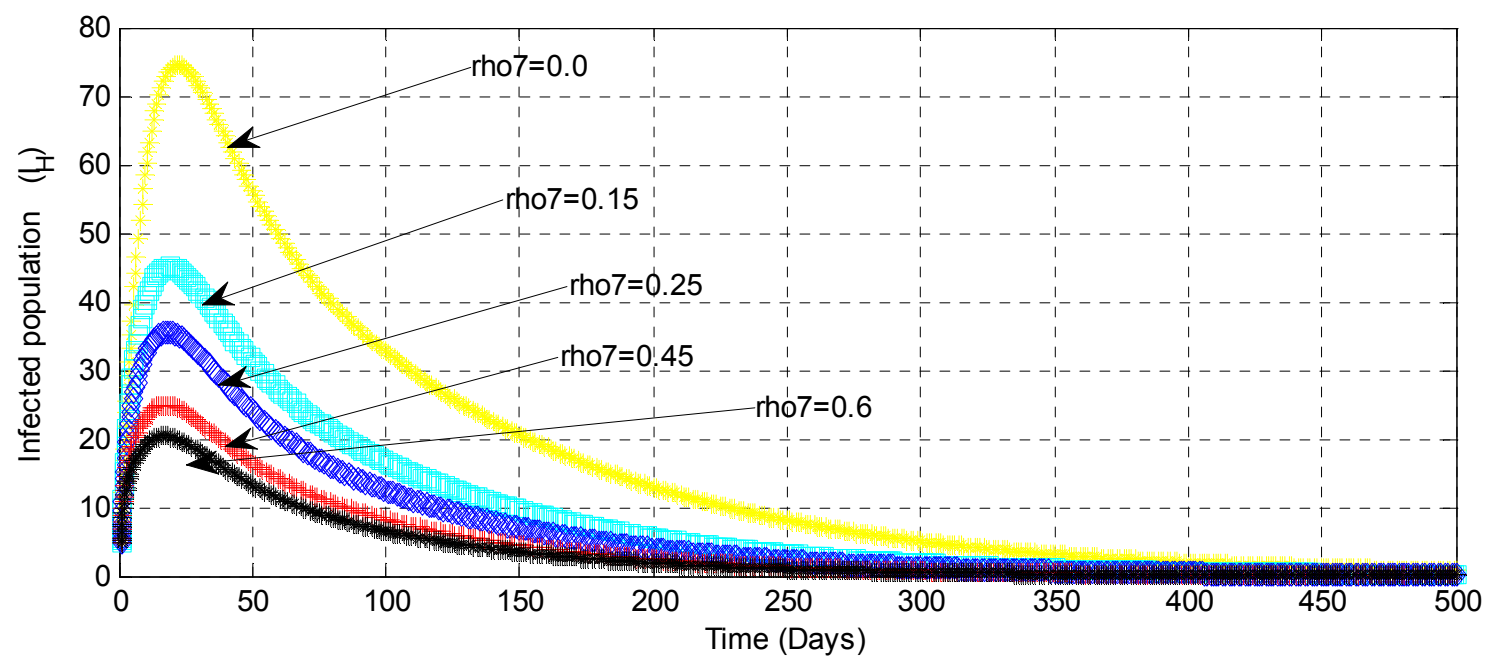

(a) 


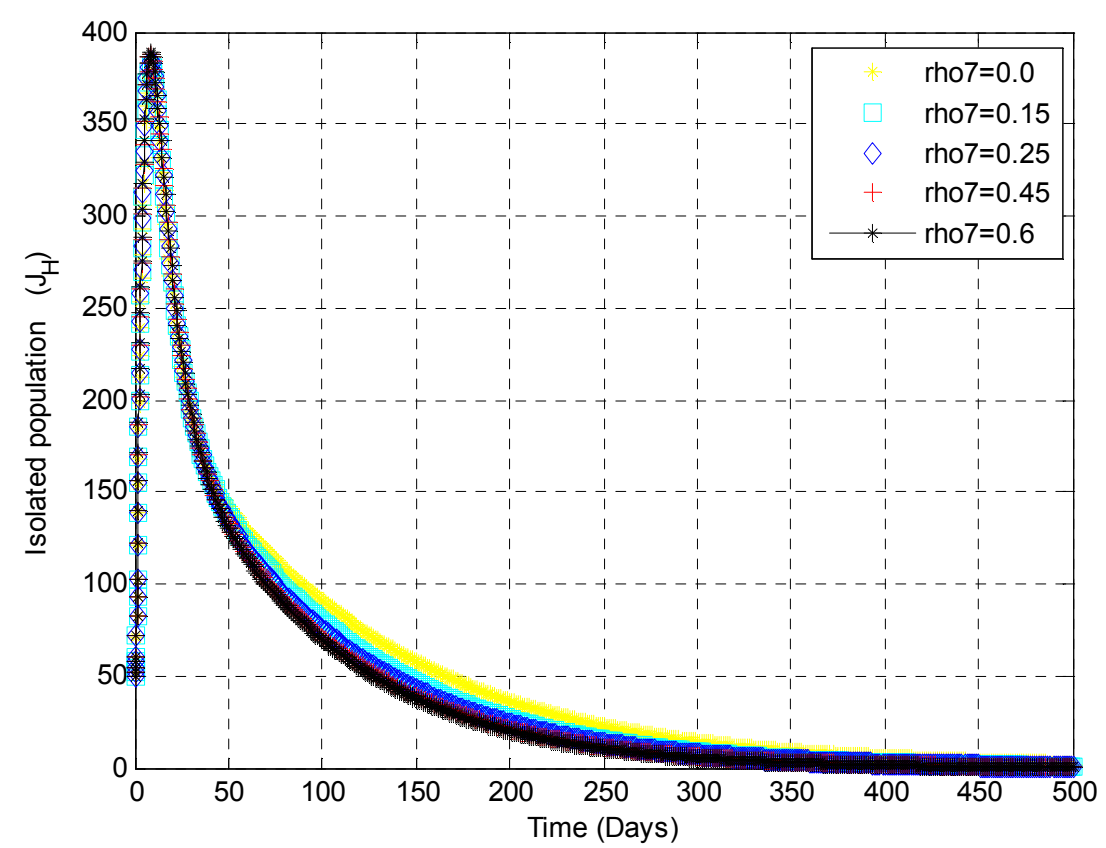

(b)

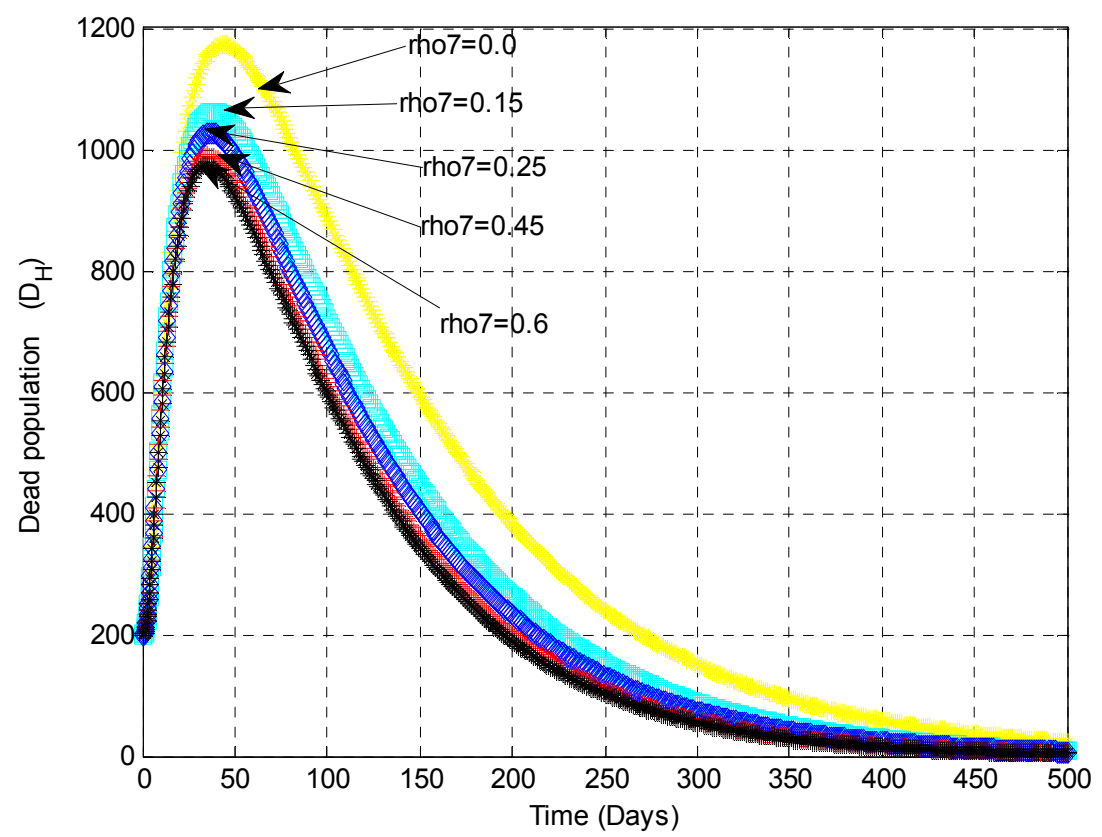

(c)

Figure 9. Simulations showing the effect of isolating Infectious humans, $\rho_{7}$, on the LASV transmission dynamics.

\subsection{Discussion}

Figure 5 revealed an exponential increase in the infected population and a sharp decrease in the number of quarantined infectious population when the proportion of exposed notquarantined humans is increased. For instance, in figure 5a, an increase in the proportion of exposed not-quarantined humans parameter from 0.0 to 0.6 doubles the number of infectious humans among the exposed not-quarantine humans from about 20 to 40 within 10 days. This scenario if left unchecked, will lead to a disease endemic state in the population. Similarly, an increase in the proportion of not- quarantined humans from 0.0 to 0.4 will definitely results in sharp decrease in the proportion of quarantined humans and consequently decreases in the proportion of quarantined infectious/isolated humans from about 680 to 400 in less than 10 days as seen in figure $5 \mathrm{~b}$. This high rise in the proportion of exposed not-quarantined humans may be attributed to high rate of ignorance and fictitious beliefs among the populace on preference to traditional medication when sick rather than the conventional orthodox medication. Hence the need for thorough sensitization/enlightenment campaign by the government/HCWs/well spirited individuals in both rural and urban settlements will prevented such people from escaping 
unnoticed into the susceptible population where the later infects viciously (especially their family members and HCWs).

In Figure 6, as the rate of which people are not quarantined increases, the infected population increases and also the number of disease induced death (death infectious compartment) increases too. From Figure 6a, when the rate of not-quarantined people, $\rho_{1}$, increases from 0.0 to 0.6 , there was an exponential increase in the number of infectious human from about 50 to 280 people, which seems not to die out of the population with time. Again, increase in the parameter, $\rho_{1}$, from 0.0 to 0.6 led to a geometric increase in the number of death infectious humans from about 100 to 2 , 250 within 100 days (see Figure 6c) and also a sharp reduction in the number of isolated humans from about 400 to 250 persons within 10 day..

Figure 7 revealed that the number of infected humans reduced drastically when the rate of quarantining the exposed human increases, this resulted to an increase in the number of isolated humans. For instance, an increase in the parameter ' $\rho_{2}$ 'from 0.0 to 0.6 resulted to a geometric decrease in the number of infected humans from about 63 to 20 within 20 days (see in Figure 7a) and also an exponential increase in the number of isolated humans from about 50 to 700 within 10 days in the population (see Figure $7 \mathrm{~b}$ ). The implication is that once a person is quarantined, he is immediately isolated and will not have the chance to infects susceptible population (especially family members or HCWs). This control measure will prevent new infections and will cause the population to achieve a disease-free state within a short period of time. This means that once a

We observed in Figure $8 \mathrm{~b}$ that there is an increase in the number of isolated humans from 50 to 450 within 15 days when the rate of isolating the quarantine infectious humans increases from 0.0 to 0.5 . The quarantine infectious humans are the quarantine humans that develop symptoms within the incubation period of Lassa virus (mostly family members of infectious humans and HCWs). Since the number of people in isolation increases, surely the number of disease induced death will increases (see Figure 8c). this is true, because there is no vaccine/drugs yet and isolation is just a preventive measure from new infections of susceptible population, not cure (only a very small proportion of isolated humans recovers at this stage at the rate of ${ }^{*} \rho_{6}$ 'due to boost of immunity). Hence, HCWs are encouraged to imbibe the use of best international safety measures at all times especially when treating patient (s) with febrile symptoms, since they are the most vulnerable humans.

Because buck of the infectious humans are scattered ignorantly among the susceptible population, hence the control parameter of intensive cracked down of isolating infectious not-quarantined humans ' $\rho_{7}^{\prime}$ by the government/HCWs as reveals in Figure $9 \mathrm{a}$ and figure $9 \mathrm{~b}$ yields an exponential increase in the number of isolated humans in the population from about 50 to 385 humans within 10 days and geometric decrease in the number of infectious people. This is true, because those isolated infectious not-quarantined humans will not have the chance again of infecting new susceptible humans especially their family members and HCWs again. For instance, an increase in the parameter, $\rho_{7}$, from 0.0 to 0.6 led to a geometric decrease in the number of infectious humans in the population from about 76 to 21 humans within 20 days (Figure 9a). Also, we observed a sharp decrease in the number of death infectious human from about 1, 195 to 998 within 35 days, which took the population about 500 days to reach disease-free state (see Figure 9c). This control measure has no doubt yields tremendous results in curbing both new infections and disease induced death from the population.

Also, we discovered a disheartening situation in the burial practices of the people in the Eastern and southern part of Nigeria. The unnecessary delay in burying corpse, the handling of corpse by morticians or relations of the deceased without wearing protective clothes, unhealthy burial procession/laying-in-state of corpse from maternal to paternal families were people emotional touches/robs the corpse in 'demonstration of love' etc has a high risk of aiding transmission of LASV from death infectious persons to a susceptible human (especially morticians/undertakers). Hence, the control parameter of early safer burial of corpse with minimal protective contact with the corpse ' $\gamma$ ', yields a positive effects in weakening the force of infection on the susceptible human.

\subsection{Conclusion}

In this paper a deterministic mathematical model for lassa fever which incorporates death infectious compartment with control is formulated. The model analysis; Well-possedness, Existence of Equilibria, Basic reproduction, existence of endemic equilibrium andbifurcation analysis was carried and analyzed. It was established that the disease-free equilibrium point is stable when the reproduction number, $\mathrm{R}_{0}<1$ and the disease will dies out with the intervention of the control measures. Numerical simulation was carried out with parametized data for Ebonyi State, Eastern Nigeria to reflect the eastern endemic region. The numerical simulation reveals that sensitization of susceptible population, quarantined of exposed humans and isolation of infectious humans, the practice of best international safety measures among health care workers, establishment of more Lassa fever diagnostic centres and precautionary burial practices remains the best control measures in the dynamic transmission of Lassa fever. 


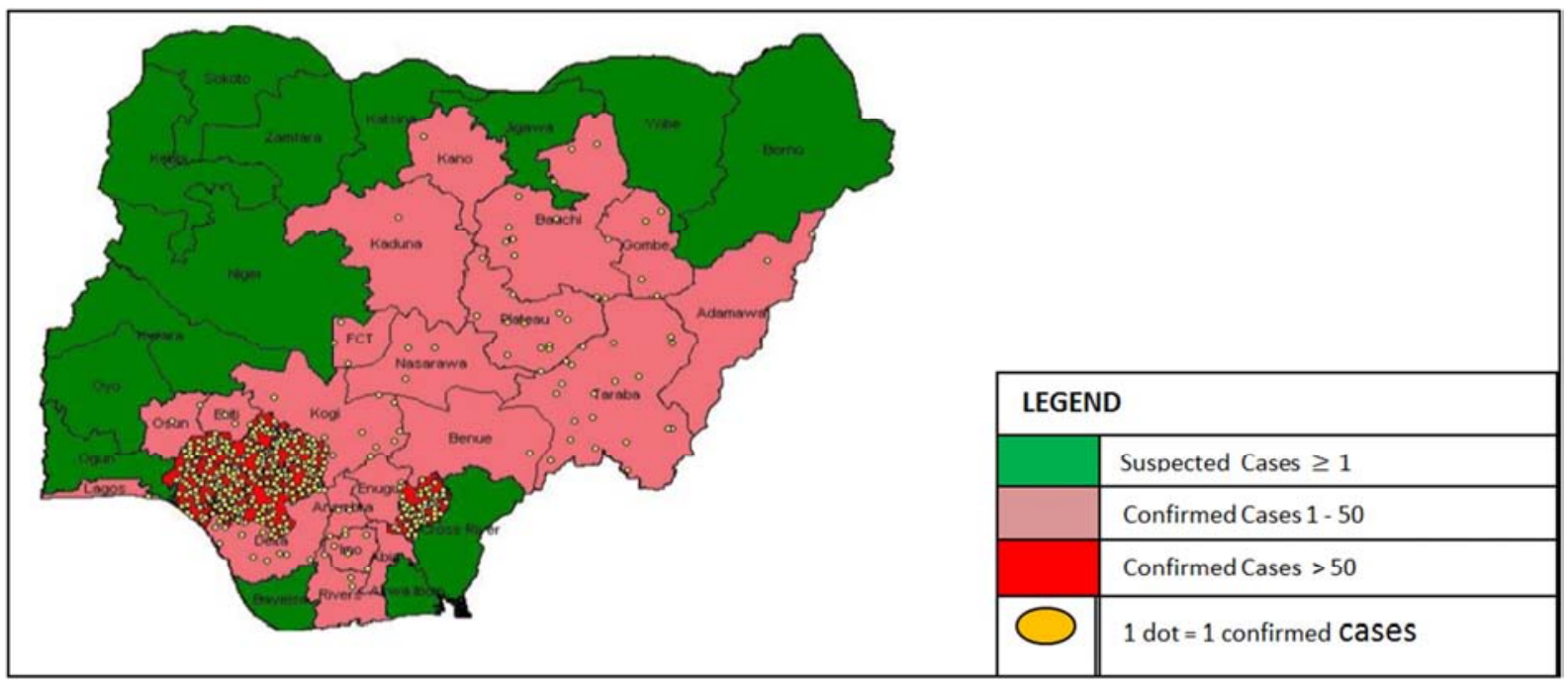

Figure 10. Showing Distribution of Confirmed Lassa Fever in Nigeria as at from January, $1^{\text {st }}-31^{\text {st }}$ December, 2018.

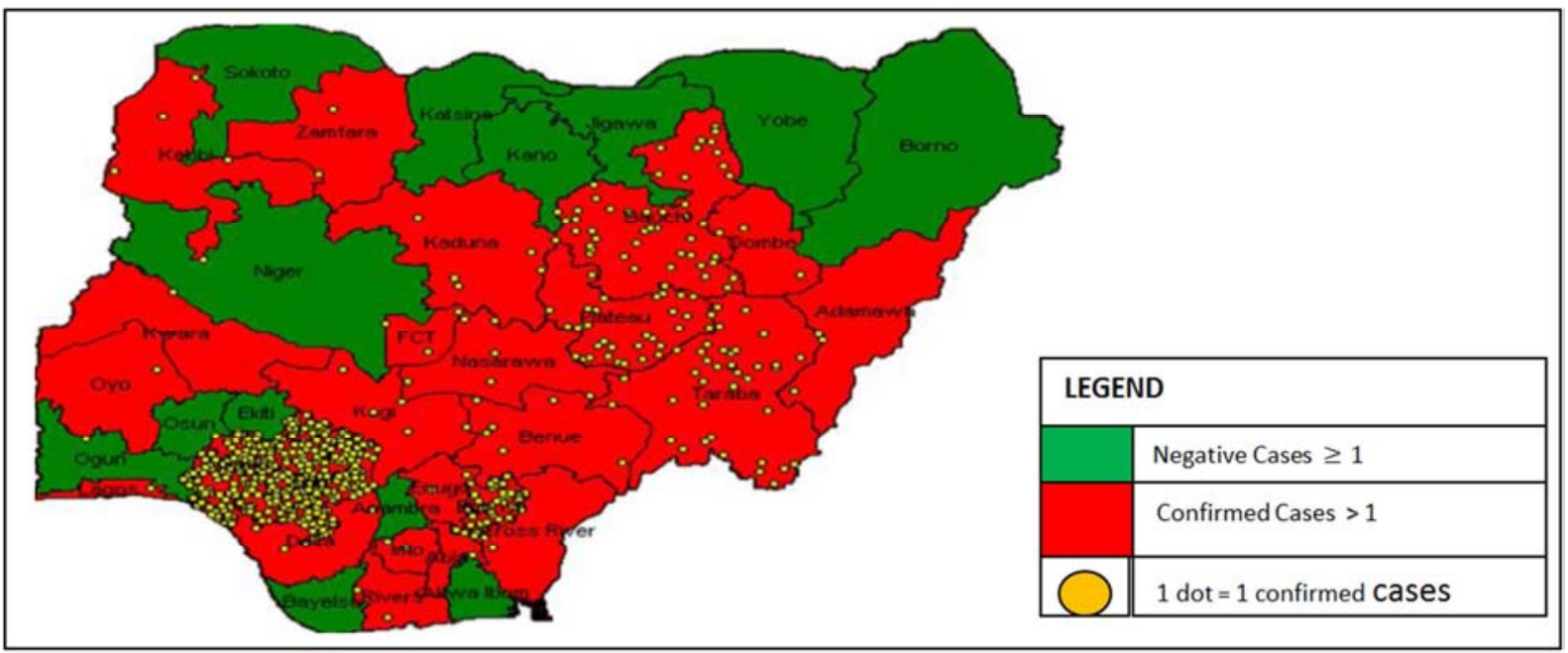

Figure 11. Showing Distribution of Confirmed Lassa Fever in Nigeria from January $1^{\text {st }}$-September 15, 2019.

\section{Acknowledgements}

We want to especially acknowledge the Nigerian Tertiary Education Trust Fund (tetfund) for sponsoring this research and Akanu Ibiam Federal \{Polytechnic, Unwana for given us the opportunity to access this research grand. Also we will like to appreciate our spouses Mrs. Stacy Dachollom Sambo and Dr. Madubueze for proof reading the manuscript and their moral support.

\section{References}

[1] Adewale, S. O., Olapade, I. A., Ajao, S. O., Adeniran, G. A. \&Oyademi, O. T. (2016). Mathematical Analysis of Lassa Fever Model with Isolation. Asian Journal of Natural \& Applied Sciences, 5 (3): 47-57.

[2] Akinpelu, F. O. and Akinwande, R. (2018). Mathematical Model for Lassa Fever and Sensitivity Analysis. Journal of Scientific and Engineering Research, 5 (6): 1-9.

[3] Bawa, M., Abdulraham, S., Jimoh, O. R. (2013). Stability
Analysis of the Disease-free Equilibrium State ofLassa Fever Disease, Int. Journal of Science and Math. Edu. 9 (2): 115-123.

[4] Castillo-Chavez C. and B. Song B. (2014). "Dynamical Models of Tuberculosis and their Applications," Mathematical Biosciences and Engineering, 1 (2): 361-404.

[5] Dahmane, A., van Griensven, J., Van Herp, M., Van den Bergh, R., Nzomukunda, Y., Prior, J., Alders, P., Jambai, A., Zachariah, R. (2014). Constraints in the Diagnosis and Treatment of Lassa Fever and theEffect on Mortality in Hospitalized Children and Women with Obstetric Conditions in a RuralDistrict Hospital in Sierra Leone. Trans. R. Soc. $\begin{array}{lllll}\text { Trop. } & \text { Med. } & \text { Hyg. } & 108 & \text { (3): } \quad 126-\end{array}$ 132.https://doi.org/10.1093/trstmh/tru009.

[6] Drosten, C., Kümmerer, B. M., Schmitz, H., Günther, S. (2003). Molecular diagnostics of viral hemorrhagicfevers. Antiviral Res. 57, 61-87. https://doi.org/10.1016/S01663542(02)00201-2.

[7] European Centre for Disease Prevention and Control, Lassa fever in Nigeria, Benin, Togo, Germany andUSA- 23, March 2016, (2016) Stockholm, https://www.thelocal.de/20160317/german-man-to-contractlassa-virus-outside-africa. 
[8] Faniran, T. S. (2017). A Mathematical Modelling of Lassa Fever Dynamics with Non-drug Compliance Rate. International Journal of Mathematics Trends and Technology, 47 (5): 305-318.

[9] Fichet-Calvet E., Rogers, D. J. (2009). Risk Maps of Lassa Fever in West Africa. PLoS Negl Trop Dis 3 (3): e388. doi: 10.1371/journal.pntd.0000388.

[10] Greenky D., Knust B., Dziuban E. J. (2018). What Pediatricians Should Know About Lassa Virus. JAMA Pediatr 172 (5): 407-8.

[11] Hallam, H. J., Hallam, S., Rodriguez, S. E., Barrett, A. D. T., Beasley, D. W. C., Chua, A., Ksiazek, T. G., Milligan, G. N., Sathiyamoorthy, V., Reece, L. M. (2018). Baseline Mapping of Lassa Fever Virology, Epidemiology and Vaccine Research and Development. Npj Vaccines 3.https://doi.org/10.1038/s41541-018-0049-5.

[12] Hamblion, E. L., Raftery, P., Wendland, A., Dweh, E., Williams, G. S., George, R. N. C., Soro, L., Katawera, V., Clement, P., Gasasira, A. N., Musa, E., Nagbe, T. K.(2018). The Challenges of Detecting andResponding to a Lassa fever Outbreak in an Ebola-Affected Setting, Int. J. Infect. Dis. 66, 65-73.https://doi.org/10.1016/j.ijid.2017.11.007.

[13] Manning, J. T., Forrester, N., Paessler, S. (2015). Lassa Virus Isolates from Mali and the Ivory CoastRepresent an Emerging Fifth Lineage. Front. Microbiol. 6, 1037.https://doi.org/10.3389/fmicb.2015.01037.

[14] Mori, Y., Notomi, T. (2009). Loop-mediated Isothermal Amplification (LAMP): A Rapid, Accurate, and CostEffective Diagnostic Method for Infectious Diseases. J. Infect. Chemother. 15, 62-69.https://doi.org/10.1007/s10156-0090669-9.

[15] Nigeria Centre for Disease Control (2018). Weekly Epidemiological Situation Report: An update of Lassafever outbreak in Nigeria. URLhttps://ncdc.gov.ng/reports/207/2019-agust-week-34.

[16] Nigeria Centre for Disease Control (2019). Weekly Epidemiological Situation Report: An update of Lassafever outbreak in Nigeria. URL https://ncdc.gov.ng/reports/207/2019-agust-week-34.

[17] Obabiyi, O. S. and Onifade, A. A. (2017). Mathematical Model for Lassa Fever Transmission Dynamics withVariable Human and Reservoir Population, International Journal of Differential Equations andApplications, 16 (1): 67-91.

[18] Ogabi, C. O., Olusa, T. V., \& Madufor, M. A. (2012).
Controlling Lassa Fever in Northern Part of Edo State, Nigeria using SIR Model. New Science Journal. 5 (12): 115-121.

[19] Okuonghae, D. \& Okuonghae, R. (2006). A Mathematical Model for Lassa Fever, Journal of the Nigerian Association of Mathematical Physics, 10: 457-464.

[20] Oloniniyi, O. K., Unigwe, U.S., Okada, S., Kimura, M., Koyano, S., Miyazaki, Y., Iroezindu, M. O., Ajayi, N. A., Chukwubike, C. M., Chika-Igwenyi, N. M., et al. (2018). Genetic characterization of Lassa virusstrains isolated from 2012 to 2016 in southeastern Nigeria. PLoS Negl. Trop. Dis. 12, e0006971.https://doi.org/10.1371/journal.pntd.0006971.

[21] Onuorah, M. O, Akinwande N. I, Nasir M. O, Ojo M. S. (2016) Sensitivity Analysis OfLassa Fever Model, International Journal of Mathematics and Statistics Studies Vol. 4, No. 1, pp. 30-49.

[22] Pemba CM, Kurosaki Y, Yoshikawa R, Oloniniyi OK, Urata S, Sueyoshi M, Zadeh VR, Nwafor I, Iroezindu MO, Ajayi NA, Chukwubike CM, Chika-Igwenyi NM, Ndu AC, Nwidi DU, Maehira Y, Unigwe US, Ojide CK, Onwe EO, Yasuda J, (2019), Development of an RT-LAMP Assay for the Detection of Lassa Viruses in Southeast and South-Central Nigeria, Journal of Virological Methods. https://doi.org/10.1016/j.jviromet.2019.04.010.

[23] Raabe, V., Koehler, J., 2017. Laboratory Diagnosis of Lassa

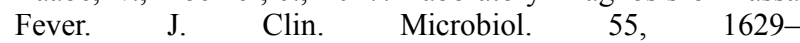
1637.https://doi.org/10.1128/JCM.00170-17.

[24] Richmond, J. K., Baglole, D. J. (2003) Lassa fever: Epidemiology, Clinical Features, and Social Consequences. British Mathematical Journal.327: 127 1-5.

[25] Tolulope, O. J., Akinyemi, S. T. and Bamidele, O. (2015) Stability Analysis of Lassa fever with Quarantineand Permanent Immunity. International Journal of Applied Science and Mathematical Theory, 1 (8): 71-81.

[26] Usman, S and Adamu, I. I. (2018). Modelling the Transmission Dynamics of the Lassa Fever Infection. Mathematical Theory and Modeling, 8 (5): 42-63.

[27] WHO. Lassa fever. Available from. 2018. http://www.who.int/en/news-room/fact-sheets/detail/lassafever.

[28] Wong, Y. P., Othman, S., Lau, Y. L., Radu, S., Chee, H. Y. (2018). Loop-Mediated Isothermal Amplification (Lamp): A Versatile Technique for Detection of Micro-Organisms. $J$. Appl. Microbiol. 124: 626-643. https://doi.org/10.1111/jam.13647. 